\title{
Nochmals über die Wirkung stark verdünnter Lösungen auf lebende Zellen.
}

Von

\section{Th. Bokoruy.}

Die merkwürdigen Beobachtungen, die man an äusserst hoch verdünnten Lösungen von gewissen Schwermetallsalzen bei ihrer Eiuwirkung auf lebende Mikroorganismen machen kann, haben den Verfasser zu dem Schlusse geführt, dass das Plasmaeiweiss dieser Zellen sich durch ein beispielloses Reaktionsvermögen gegen Kupfersalze, Quecksilbersalze, Silbersalze auszeichnet, welches dahin führt, dass noch aus Lösungen von 1: 100 Millionen das Metall herausgenommen und dureh chemische Bindung in den Plasmen angehäuft wird, womit dann allmählich der Tod eintritt. Man kann von solehen Metallsalzen sagen, dass sie in hohem Masse "giftig" für die betreffenden Mikroorganismen seien. Wenn Spirogyren durch Kupfervitriollösungen oder durch Höllensteinlösungen von 1: 100 Millionen, sogar $1: 1000$ Millionen noch geschädigt werden, falls man genügend Lösung anwendet, so ist daran natürlich nicht die blosse Berührung und Durehtrănkung mit dieser Lösung schuld, die ja nur minimalste, chemisch nicht nachweisbare Mengen von Kupfer oder Silber enthält, sondern die chemische Bindung des Metalles im Plasma ${ }^{1}$ ), die zur Bildung einer unlöslichen oder jedenfalls nicht diffusionsfäbigen Metalleiweissverbindung und zur Aufsammlung ${ }^{2}$ ) des $\mathrm{Cu}$ bis zur tödlichen Menge führt; dieser Vorgang muss, wie jede chemische Reaktion, die unlösliche Körper zutage fördert, immer weiter fortschreiten, bis zur völligen Entkupferung oder Entsilberung der Flüssigkeit. Er gleicht darin dem schon längst bekannten Aufsammlungsvermögen der Algenzellen für die im Wasser gelösten unorganischen und organischen Nährstoffe, das bis zur völligen Beraubung des Wassers führen kann.

1) Durch Schwefelwasserstoff kann die Anwesenheit des Kupfers, noch leichter die des Silbers, nachgewiesen werden, wemn eine genügende Anhäufung stattgefunden hat.

2) 0 . Loew hat auf diesen Punkt in einer Anmerkung aufmerksam gemacht in "Chem. Energie der lebenden Zellen" S. 167. 
Nur handelt es sich bei dem Kupfer oder Silber um ein Gift und bei den Nährstoffen um die Bildung der verschiedensten unlöslichen und nicht diosmierenden Baustoffe für den Zellenleib.

Diese Art von Giftigkeit, wie wir sie bei den genannten Schwermetallsalzen, nicht aber bei allen anderen vorfinden, stellt jedenfalls einen besonderen recht bemerkenswerten Fall der Giftwirkung dar, der bis jetzt meines Wissens nicht scharf genug unterschieden worden ist. Die Giftigkeit ist hier in einer auffallend starken chemischen Verbindungsfähigkeit des Giftstoffes mit dem Plasmaeiweiss oder umgekehrt begründet, einer Verbindungsfähigkeit, die keine Grenze durch hohe Verdünnung zu kennen scheint.

Es schien mir von grossem Interesse zu sein, wie sich andere Giftstoffe, von denen auch eine chemische Verbindungsfähigkeit mit dem Plasmaeiweiss angenommen werden muss, verhalten; bei welcher Verdünnung sie aufhören zu reagieren; welche Zellen etwa besonders empfindlich dagegen sind.

Wenn sich feststellen lässt, dass eine grosse Differenz in der Verbindungsfähigkeit der Stoffe, d. h. in der Konzentration, bei welcher sie noch schädlich wirken, herrscht, und dass die sehr reaktionsfähigen noch bei den höchsten Verdünnungen sich verbinden, aber nur innerhalb längerer Zeit und bei Anwendung einer geringen Menge lebenden Plasmas töten, während die weniger reaktionsfähigen nur bei relativ hohen Konzentrationen schädlich und tödlich wirken, in grössern Verdünnungen aber weder bei langer Einwirkung noch bei Darbietung geringster Mengen von lebenden Zellen eine Einwirkung. äussern, so liegt darin vielleicht eine kleine Erweiterung unserer Kenntnisse über die Giftwirkung.

Die verschiedene Resistenz, welche die einzelnen Organismengattungen und Zellen aufweisen gegenüber den einzelnen Giften, ist ebenfalls sehr beachtenswert. Gar manche spezifische Giftwirkung kann vielleicht auf diese Weise erklärt werden.

Die Aufsammlung des Giftes in einzelnen Zellenarten eines komplizierten voluminösen Organismus sowie das Nichtreagieren anderer Zellarten kann dazu führen, relativ verschwindend kleine Dosen eines Giftes noch wirksam zu machen.

$\mathrm{Ob}$ ein Gift sich mit dem Plasma verbindet, kann in manchen Fällen direkt an den entstehenden Ausscheidungen oder Färbungen, in anderen Fällen durch nachträgliche Einwirkung eines Reagens (z. B. Schwefelwasserstoff bei den Schwermetallen) erkannt werden. 
Lässt sich beides nicht gebrauchen, so muss man in der T'atsache einer Giftwirkung stark verdünnter Lösungen binmen langer Zeit und auf wenig Versuchsmaterial einen Beweis für die Verbindungsfähigkeit des betreffenden Stoffes erblicken.

Zunächst schien es dem Verfasser zweckmässig zu sein, die Wirkung einiger Farbs toffe (Anilinfarben) auf die Mikroorganismen zu studieren, von denen schon lange bekannt ist, dass sie sich mit Eiweiss und auch anderen organischen Stoffen "verbinden". Ob das eine wirkliche chemische Verbindung oder bloss eine molekulare Anlagerung ist, spielt zunächst keine Rolle. Die Hauptsache hierbei ist, dass eine deutliche Wirkung zutage tritt, und dass man diese Farbstoffe noch bei Verdünnung $1: 1000$ und 1:10000 unter dem Mikroskop als gefärbt erkennt und somit eine etwa erfolgende Aufspeicherung durch Mikroorganismen leicht bemerkt. Bis zu solchen Mengen wie $0,1 \%$, ja sogar noch mehr, wird der Farbstoff aus hoch verdünnten Lösungen durch die Zelle im Laufe der Zeit allmählich angehäuft.

Es ergab sich bei diesen Versuchen, dass viele Zellen ein staunenswertes Aufsammlungsvermögen für Anilinfarben besitzen, welches fast an das Verhalten der Spirogyren gegen Kupfer- und Quecksilbersalze erinnert.

Von grossem Interesse ist die tödliche Wirkung ausserordentlich verdünnter Lösungen von Anilinfarben auf verschiedene Mikroorganismen aus dem Tier- und Pflanzenreich. Dieselbe äussert sich aber nur dann, wenn man grosse Mengen von Lösung und minimale Quantitäten von lebenden Zellen anwendet und die Farbstofflösung lange Zeit auf die Zellen wirken lässt.

Man erhält dann ähnliche staunenerregende Giftwirkungen wie mit den berüchtigten Giften Sublimat, Höllenstein usw.

Nur einige wenige Versuche seien hier angeführt:

Lässt man $1 \%$ ige Diamant-Fuchsin-Lösung in der gewöhnlichen Weise - mit einem Tropfen Lösung auf dem Objektträger und einer Pinzettespitze voll Schlamm aus alten Algenkulturen - auf niedere Tiere und Pflanzen, wie sie in Wasser mit halb oder ganz abgestorbenen Algenkulturen vorkommen, einwirken, so bemerkt man binnen wenigen Minuten eine schädliche Einwirkung. Infusorien zeigen zuckende Bewegungen, desgleichen Anguillula-Arten; nach etwa 10 Minuten hören die Bewegungen auf, die Tiere sind tot und färben sich lebhaft rot. Bakterien, Hefezellen, Diatomeen usw. sterben ebenfalls bald $a b$ und färben sich intensiv rot. 
Nimmt man nicht ein en Tropfen Lösung, sondern viele, etwa 1 ccm Farbstofflösung, wozu man am besten ein kleines Glasnäpfehen verwendet, und bringt einen Tropfen jenes Scblammes binein, so ändert sich der Erfolg insofern, als nun die Vergiftung und Färbung augenblicklich eintritt, da eine ausgiebige Farbstoffspeicherung in allen Zellen sofort beginnt, während im vorigen Falle einzelne Partien der Algen und niederen Tiere den Farbstoff grossenteils an sich reissen, so dass den anderen nur mehr eine stark verdünnte Lösung zu Gebote steht.

Nimmt man von vornherein $0,1 \%$ ige, also zehnfach verdünnte Lösung, so bemerkt man bei der zuerst beschriebenen Versuchsanstellung die erwähnten giftigen Wirkungen nicht mehr, wenigstens an den Infusorien, Würmern, Insektenlarven; die vorhandenen Algen sterben langsam ab, indem sie den Farbstoff aus dem Tropfen Lösung an sich reissen.

Ist aber die Farbstofflösung in grossem Überschuss da, wie bei der zweiten Versuchsanstellung, so werden die Mikroorganismen binnen wenigen Minuten getötet und gefärbt.

Ähnlich ist es mit $0,01 \%$ iger $\mathrm{Fuchsinlösung:} \mathrm{Bei} \mathrm{der} \mathrm{ersten}$ Art der Versuchsanstellung nur Färbung der Algen, bei der zweiten binnen kurzer Zeit überall Färbung der Mikroorganismen und Tod.

In letzterem Falle sieht man dann bäufig bereits schwach gefärbte Infusorien sich noch langsam fortbewegen, bis die Anhäufung des Farbstoffes den erforderlichen Grad erreicht hat; das Tier nimmt zusehends tiefere Färbung an und geht dann in dauernde Unbeweglichkeit über.

$\mathrm{Zu}$ bemerken ist weiterhin, dass nicht alle Infusorienarten sich gleich rasch färben. Bei den Anguillula-Arten tritt eine Färbung sehr langsam ron dem einen Körperende her ein.

Nimmt man $0,1 \%$ ige Methylviolettlösung in grossem Überschuss (zweite Art der Versuchsanstellung), so werden die Mikroorganismen ziemlich rasch getötet.

Ähnlich mit 0,01\% iger Methylviolettlösung.

Sogar $0,001 \%$ ige Methylviolettlösung ist bei 12 stündiger Einwirkung imstande, sämtliche Infusorien usw. abzutöten. Die Farbstoffspeicherung ist dabei eine sehr beträchtliche, wie man aus dem Unterschied zwischen dem stark gefärbten Infusorienleib und der farblosen Lösung erkennt. 
Auch hier ist zu bemerken, dass nicht alle Zellen den Farbstoff gleich rasch aufnehmen.

Viktoriablau zeichnet sich vor anderen Farbstoffen dadurch aus, dass dasselbe von Mikroorganismen, z. B. Hefe, völlig aus der Lösung entfernt wird bis zur gänzlichen Entfärbung der Flüssigkeit.

In 0,01\% iger Lösung des Farbstoffes wird durch Infusorien so viel Farbstoff gespeichert, dass binnen einer Viertelstunde eine deutliche Blaufärbung des Leibes dieser Tiere sichtbar wird, während an der Lösung selbst die Färbung unter dem Mikroskop nicht erkennbar ist.

Demgemäss sterben die Infusorien in dieser hoch verdünnten Lösung bald ab. Es ist dabei sehr deutlich zu sehen, wie der Infusorienleib noch während des Lebens der Tiere (erkennbar an ihrer Bewegung) sich färbt, und dass der Tod erst eintritt, wenn die Färbung ein gewisses Mass erreicht hat.

Mit Safranin kann man bei genügender Lösung leicht konstatieren, dass $0,1 \%$ ige Lösung fast augenblicklich die Infusorien unter starker Färbung derselben abtötet. Sogar 0,01\% ige Lösung wirkt, im Überschuss angewendet, auf viele Infusorien binnen kurzer Zeit tödlich, indem immer mehr Farbstoff angesammelt wird.

Bei Methylenblau tritt die Farbstoffspeicherung etwas langsamer ein. Denn man kann noch längere Zeit ungefärbte Infusorien in $0,01 \%$ iger Methylenblaulösung umherschwimmen sehen - neben gefärbten.

In anderen Fällen ist aber das Methylenblau durch besonders starkes Färbungsvermögen ausgezeichnet. So wird Methylenblau besonders leicht von lebender Nervensubstanz (dem Achsenzylinder) aufgenommen, so dass es Ehrlich für möglich hielt, bestimmte Nervenendigungen in noch lebendem Zustande zu verfolgen. Merkwürdige tinktorielle Unterschiede zeigen sich dabei; so färbt sich die Spiralfaser der sympathischen Ganglienzellen blau, der gerade Fortsatz derselben aber nicht.

Da die Anilinfarben in neuerer Zeit als ziemlich wenig giftig taxiert werden (falls sie rein sind), so sind vorausstehende Schilderungen wohl von einigem Interesse.

Wohl die meisten Physiologen würden es nicht für möglich gehalten haben, dass man mit Farbstofflösungen von $1: 100000$, ja sogar 1:1 Million lebende Zellen mit voller Sicherheit abtöten könne. 
Nochmals über die Wirkung stark verd. Lösungen auf lebende Zellen. 179

Und doch ist der Nachweis hierfür leicht zu erbringen, wenn man die Versuchsmethode und die Objekte richtig wählt.

Es ist auf Zeit und Menge genau zu achten. Denn aus hoch verdünnten Lösungen wird natürlich der Farbstoff erst im Laufe der Zeit bis zur tödlichen Menge gespeichert.

Wenn ferner die Gesamtmenge des Farbstoffes eine zu geringe ist, so können sich zwar einige Zellen etwas färben, aber zum allgemeinen Absterben kommt es nicht.

Ich versuchte an der käuflichen Presshefe mit verschiedenen Farben die Menge des äussersten Falles zu bindenden Farbstoffes festzustellen.

Von Fuchsin vermochte die Hefe ca. 1\% ihres Gewichtes zu binden; sie nahm dabei eine intensive Färbung an. Es ist also nicht wenig Farbstoff, den die Zelle aufnimmt; sie erscheint dann auch unter dem Mikroskop bei 200 facher Vergrösserung intensiv gefärbt.

Bis zu einer ähnlichen Stärke färben sich auch Infusorien, wenn sie in verdünnte Farbstofflösungen gebracht werden und diesen Farbstoff in sich aufspeichern. Es ist übrigens nicht zu bezweifeln, dass dieselben schon absterben, bevor sie die ganze mögliche Farbstoffmenge in sich aufgespeichert haben.

Wir müssen die Giftigkeit der Anilinfarben zweifellos mit ihrem Färbungsvermögen in direkten Zusammenhang bringen. Wenn ein Farbstoff das Protoplasma nicht zu färben vermag, so ist er unschädlich; verbindet er sich aber damit, dann erfolgt eben durch diesen Vorgang das Absterben.

Die Frage nach der Giftigkeit der Anilinfarben fällt also mit der nach ihrem Färbungsvermögen zusammen. Die verschiedenen Zellen und Farben verhalten sich hierin durchaus nicht gleich. So berichtet Ehrlich, dass zwar Metbylenblau, nicht aber Fuchsin, Methylviolett, Saffranin, den Achsenzylinder zu färben vermögen.

$\mathrm{Zu}$ unterscheiden ist übrigens die Färbung, welche an dem bereits getöteten Plasma eintritt. Es ist wohl möglich, dass sich ein Farbstoff mit dem getöteten verbindet, dem lebenden aber nicht, besonders wenn durch die Tötungsart eine Veränderung der „Tektonik" herbeigeführt wurde.

Nachdem nun an den Farbstoffen die Verbindungsfähigkeit des Plasmas und das damit erfolgende Absterben nachgewiesen ist, gehe ich zunächst zu einem Stoffe über, der schon seit langer Zeit als 
allgemein verbindungsfähig gegenüber den Eiweissstoffen gilt, dem Tannin oder der gewöhnlichen Gerbsäure, ferner zu einigen anderen Gerbstoffen.

In $1 \%$ igen Lösungen der Gerbsäure sterben Paramäcien augenblicklich ab unter körniger Trübung ihres Körpers. Offenbar reagiert das Plasmaeiweiss sofort mit dem Tannin.

Auch in $1 \%$ iger Tanninlösung wird augenblicklich eine Reaktion sichtbar; die grösseren Individuen nehmen sehr bald eine Trübung und eine taumelig-drehende Bewegung an; nach 3 Minuten hört die Bewegung ganz auf, im Innern ist neben den körnigen Trübungen eine ziemlich grosse Vakuole sichtbar; zuckende Bewegungen, die von Zeit zu Zeit eintreten, zeigen an, dass das Leben nicht ganz erloschen ist. Die kleineren (jüngeren) Individuen scheinen aber noch gar nicht von der Giftwirkung betroffen zu sein. Auch nach 10 Minuten kann man diese Individuen noch lebhaft umherschwärmen sehen, während die anderen völlig abgestorben sind und kugelige Gestalt mit grosser Vakuole im Innern erkennen lassen (zuvor sind sie spitz und schmal eiförmig).

In $0,01 \%$ iger Lösung der Gerbsäure sterben die Infusorien sogar binnen 24 Stunden nicht ab. Sie sind nachher noch lebhaft beweglich und in ihrem Aussehen unverändert.

Lässt man so einen Versuch mit $0,01 \%$ iger Gerbsäurelösung bis auf die Hälfte ungefähr eintrocknen (durch freiwillige Verdunstung), so stirbt ein Teil der Infusorien unter starker Trübung ihres Körpers; die Trübung ist natürlich dadurch bedingt, dass nun die unlösliche Verbindung zwischen Eiweiss und Gerbsäure entstanden ist.

Die Grenze der Reaktionsfähigkeit liegt also hier ungefähr bei $0,05 \%$ Gerbsäuregehalt in der Lösung, was als relativ geringe Empfindlichkeit des betreffenden Plasmas gegen Gerbsäure bezeichnet werden muss.

Immerbin gibt es noch weniger empfindliche Organismen; so hat man z. B. gefunden, dass Schimmelpilze durch $1 \%$ ige Gerbsäure nicht getötet werden, sondern dieselbe sogar als Nahrung benutzen.

Mit Katechugerbsäure, einem braunen Pulver, das sich in Wasser beim Erwärmen löst und beim Erkalten der 1\%igen Lösung zum Teil ausseheidet, während die 0,1\% \%ge Lösung klar 
Nochmals über die Wirkung stark verd. Lösungen auf lebende Zellen. 181 bleibt, kann man ähnliche Erfahrungen machen; mit 1\% iger Lösung sterben die Infusorien augenblicklich unter starker Trübung ab, mit $0,1 \%$ erst binnen einigen Minuten.

Moringerbsäure ist ein gelbbraunes Pulver, das sich beim Lösen ähnlich verhält wie die Katechugerbsäure.

Ihre $1 \%$ ige Lösung tötet ebenfalls die Infusorien augenblicklich ab unter starker körniger Trübung. 0,1\% ige Lösung braucht dazu einige Minuten; dann sind erst die weniger widerstandsfähigen Individuen abgestorben; andere bewegen sich noch lebhaft hin und her.

Da die Gerbsäuren zu den mehrfach hydroxylierten Benzolen in naher Beziehung stehen, so sei hier an meine schon neulich publizierten Versuche (dieses Archiv Bd. 108 S. 123) an Hydrochinon und Pyrogallol erinuert.

In $0,1 \%$ iger Hydrochinonlösung bleiben Algen nicht einmal 24 Stunden am Leben; nach Ablauf dieser Zeit sind sämtliche Protoplasten kontrahiert, die Fäden ohne Turgor. Sogar in 0,01 \% starben die Algenfäden binnen drei Tagen völlig $a b$.

Äbnlich verhält sich's mit dem Pyrogallol.

Diese beiden Substanzen sind also giftiger als die Gerbsäuren, bei denen $0,01 \%$ ige Lösung nicht mehr wirksam ist.

Man hat vermutet, dass die Sauerstoff absorbierende Kraft des Pyrogallols und Hydrochinons an dieser Giftwirkung teilweise schuld sei.

Meine Versuche mit Hefe haben das nicht bestätigt; denn die Hefe wird durch diese Substanzen auch dann getötet, wenn man die Sauerstoffatmung durch Zusatz von Zucker und damit eintretende Gärung ausschaltet, also durch letztere Energiequelle ersetzt.

Es bleibt somit nichts anderes übrig, als eine unmittelbare Giftwirkung dieser Substanzen anzunehmen, ähnlich wie bei dem Phenol ${ }^{\boldsymbol{x}}$ ).

Durch den Eintritt einer Karboxylgruppe scheint die Giftigkeit herabgesetzt zu werden; darum ist Pyrogallol und Hydrochinon giftiger als Tannin (Digallussäure).

1) Phenol (Karbolsäure) ist übrigens bei weitem nicht so stark giftig; denn in $0,1 \%$ iger Lösung kann man noch nach Tagen lebende Infusorien antreffen. 
<smiles>OC1CCCCC1O</smiles>

Hydrochinon<smiles>OC1CCCCC1(O)O</smiles>

Pyrogallol<smiles>O=C(O)C1CC(O)C(O)C(O)C1O</smiles>

Gallussäure

Da die Proteinstoffe in ihrem chemischen Charakter am meisten den Amidosäuren ähneln (0. Loew), so können sie sich sowohl mit Säuren als mit Basen verbinden und damit salzartige Verbindungen eingehen.

Geschieht das mit den Eiweissstoffen des lebenden Protoplasten, so wird das Störungen mit sich bringen, welche zum Tode führen.

Da auch hier eine unlösliche Verbindung (ein Acidalbumin) gebildet wird, so ist zu erwarten, dass das Protoplasma gegenüber sehr verdünnten Lösungen eine aufsammelnde, bis zur beiderseitigen Sättigung fortschreitende Wirkung ausübt, vorausgesetzt, dass die Reaktionsfähigkeit bei grösseren Verdünnungen nicht schwindet.

Lässt man $1 \%$ ige Schwefelsäure auf Infusorien einwirken, so tritt der Tod augenblicklich ein.

Gegen $0,1 \%$ ige Schwefelsäure verhalten sich Infusorien ebenso. Dagegen reagieren manche Fadenalgen nicht augenblicklich auf diese Lösung.

In $0,01 \%$ iger Schwefelsäure sah ich momentan keine Reaktion der Infusorien; nach einer Viertelstunde auch noch nicht. Nach 24 Stunden waren alle Mikroorganismen noch am Leben; Spirogyren und Conferven vegetierten ungestört weiter, Oscillarien führten ihre Schwingungen mit den Fadenenden aus, pflanzliche grüne Schwärmer trieben sich in grosser Menge äusserst behend herum, Infusorien, Rädertierchen, kleine Anguillulen usw. waren aufs lebbafteste in Bewegung.

Da nun die 0,01\% ige Schwefelsäure in solcher Menge angewendet worden war, dass sie ausgereicht hätte, um alle Mikroorganismen zu töten, so müssen wir annehmen, dass die Schwefelsäure bei dieser Verdünnung gar nicht mehr mit dem Plasmaeiweiss zu reagieren vermag und aus diesem Grunde unwirksam bleibt. Eine Aufsammlung des Giftes ist hier nicht möglich, weil eben die chemische Reaktion überhaupt nicht einsetzt.

Es schien mir eher, als ob die schwache Säuerung des Versuchswassers eine Art Reiz auf die Mikroorganismen ausgeübt hätte; sie 
Nochmals über die Wirkung stark verd. Lösungen auf lebende Zellen. 183

sahen frischer aus als zuvor, die beweglichen schienen viel rascher umherzuschwimmen als vorher.

Da die Schwefelsäure bei Verdünnung $0,1 \%$ zwar Infusorien augenblicklich tötet, aber Algen nicht, und da ferner $0,01 \%$ als Anreiz für lebhaftere Bewegung usw. zu wirken scheint, so kann man davon sagen, was O. Loew in "Natürl. System der Giftwirkungen" S. 9 über Gifte im allgemeinen sagt: „Ein Gift, welches für alle Arten von Lebewesen bei einer gewissen Konzentration tödlich wirkt, wird bei weitgetriebener Verdünnung den resistenteren Zellen nicht mehr verhängnisvoll werden, sondern nur den labileren. Ja, jenseits einer bestimmten Grenze der Verdünnung üben Gifte oft Reizerscheinungen aus, wodurch gewisse Funktionen (der Gärvorgang bei Sprosspilzen z. B.) beschleunigt werden" (Hug 0 , Schulz, Biern a cki).

Anders als Schwefelsäure verhält es sich mit der Salzsäure hinsichtlich der schädlichen Konzentration.

In 0,1\%iger Lösung macht sie augenblicklich alle Beweglichkeit der Infusorien, Pflanzenschwärmer usw. verschwinden.

In $0,01 \%$ iger Lösung sieht man ebenfalls binnen wenigen Minuten alle Bewegung aufhören.

Bei $0,001 \%$ sogar hörten Schwärmsporen und Infusorien zu meinem Erstaunen auf sich zu bewegen.

Da übrigens der Magen des Menschen und der Tiere 0,2\% ige Salzsäure verträgt, so müssen die auskleidenden Zellen dieses Organes offenbar eine relativ hohe Unempfindlichkeit gegen Salzsäure besitzen.

Ähnlich verhält es sich in diesem Punkte - verschiedene Resistenz der Zellen gegen Gifte - mit der Schwefelsäure. Denn von einigen Meeresschnecken ist bekannt, dass sie aus Drüsenzellen 2-3\% ige Schwefelsäure ausscheiden.

Milzbrandbazillen sollen 48 Stunden lang eine $1 \%$ ige Salzsäure vertragen können (Dyrmont), während der Cholerabazillus schon gegen $0,1 \%$ ige Salzsäure empfindlich ist.

Die „Empfindlichkeit" richtet sich offenbar nach der Reaktionsfähigkeit. Manches Plasmaeiweiss verbindet sich schon bei $1 \%$ Verdünnung der Säure nicht mehr mit dieser, manches aber leicht.

Was die organischen $S$ äuren anbetrifft, so sollen dieselben im allgemeinen schwächer wirken.

Nach meinen Beobachtungen bringt $1 \%$ Weinsäure sofort 
alle Bewegungen der Infusorien und Pflanzenschwärmer zum Stillstand.

Auch in $0,1 \%$ hört die Bewegung der Schwärmer und Infusorien sofort auf, einige kleine Anguillulen und Distomen aber setzen ihre Bewegungen, wenn auch erstere krampfhaft, fort. Anguillulen sah ich sogar nach 24 Stunden noch in lebhaft schlängelnder Bewegung. Alles andere, auch Algen wie Spirogyren, Conferven, war nach 24 Stunden abgestorben.

In $0,01 \%$ bleibt zunächst alles unverändert. Nach 24 Stunden sind die Infusorien und andere kleine Tiere noch unverändert beweglich; die Algen (Spirogyren und Conferven) noch zum Teil lebend, zum kleineren Teil abgestorben, oft in ein und demselben Faden lebende und tote Zellen gemischt.

Meines Erachtens können die verschiedenen Resultate nur so gedeutet werden, dass die einen Plasmaarten sich mit 0,1-oder $0,01 \%$ iger Weinsäure zu verbinden vermögen, die andern nicht, und dass sogar zwischen Individuen derselben Art (Zellen desselben Spirogyrafadens) ein Unterschied hinsichtlich der Resistenz besteht. Mit $1 \%$ iger Weinsäure reagiert jedes der geprüften Plasmen.

Von den Mineralbasen untersuchte ich zunächst das Calci umbydroxyd, sogenanntes Kalkwasser, das ich bis $0,1 \%$ Gehalt an $\mathrm{Ca}(\mathrm{OH})_{2}$ verdünnte.

Bei Einwirkung einer 0,1\% igen Lösung dieser Base stellten die Infusorien augenblicklich ihre Bewegung ein; Distomen kugelten sich zusammen und waren binnen weniger Minuten bewegungslos. Die vorhandenen Fadenalgen zeigten binnen wenigen Minuten ein teilweises Absterben. Anguillulaarten sah ich nach 5 Minuten noch in Bewegung. Nach 24 Stunden waren alle Mikroorganismen getötet, mit Ausnahme der am Rande des Deckglases gelegenen. Hier hatte sich ein Niederschlag von kohlensaurem Kalk gebildet, die Base war also unwirksam geworden. Demgemäss sah man hier sogar noch lebende, lebhaft bewegliche Infusorien ${ }^{1}$ ).

Dass das Calciumbydroxyd aber auch bei grösserer Verdünnung noch mit manchen Plasmaarten sich zu verbinden vermag, zeigen Spirogyren, die man mit Kalkwasser töten kann, wenn man dasselbe bis zu einem Gehalt von $0,015 \%$ verdünnt $(0$. Loew).

1) Offenbar waren diese nach der ersten Betäubung wieder erwacht und fanden nun eine ungiftige normale Umgebung vor. 
Kalkwasser von $0,01 \%$ bringt zunächst nach meinen Beobachtungen keine bemerkbaren Veränderungen hervor an den öfters erwähnten Schlammorganismen. Auch nach Ablauf von 24 Stunden zeigt sich keine Abnahme in der Bewegung der Infusorien und anderer beweglicher Mikroorganismen. An den vorhandenen Fadenalgen bemerkte ich nur ein teilweises Absterben.

Nach Liborius genügt ein Gehalt von $0,0074 \%$ Ätzkalk in verdünnter Bouillon, um Typhusbazillen zu töten; bei Cholerabazillen $0,0246 \% \mathrm{CaO}$.

Auffallend ist eine Angabe von Kit a s a to (Z. Hyg. Bd. 3, S. 118) wonach Typhusbazillen in Nährgelatine noch wachsen, wenn dieselbe $0,1 \%$ Kaliumhydroxyd enthält, Cholerabazillen noch bei $0,14 \%$, nicht mehr bei $0,18 \%$.

Denn wenn man sonst $0,1 \%$ ige Kalilauge auf Mikroorganismen, Wasserpflanzen und Wassertiere einwirken lässt, so sterben dieselben fast augenblicklich ab.

In $0,01 \%$ iger Kalilauge sogar schienen mir Infusorien, die ich in einem Pflanzenaufguss gezogen hatte, fast augenblicklich auf die geringe Alkalimenge (als Reizmittel) zu reagieren. Dann aber zeigte sich keine weitere Störung mehr. Nach 24 Stunden waren die Infusorien noch am Leben und lebhaft beweglich. Da nun viele Infusorien in paarweiser Verschmelzung angetroffen wurden, scheint die Spur Kali in jener $0,01 \%$ igen Lösung diesen Vorgang zu begünstigen.

Also tritt bei dieser Verdünnung keine chemische Bindung des Alkalis im Plasma mehr ein. Die chemische Reaktion setzt überhaupt nicht ein, kann also auch binnen 24 Stunden nicht fortschreiten und die Zelle töten.

Jene obenerwähnte Angabe, dass Typhus- und Cholerabazillen auf Nährsubstraten mit $0,1 \%$ Kali noch wachsen, ist übrigens wohl sicher darauf zurückzuführen, dass das Alkali zum grossen Teil von der Gelatine gebunden wird. Denn dass eine Zelle $0,1 \%$ Kali lange verträgt, widerspricht allen sonstigen Erfahrungen.

Es verhält sich mit diesem Falle wohl ähnlich wie mit der anfangs rätselhaft erscheinenden Angabe der Hefereinzüchter, dass Hefespuren in mineralischen Nährlösungen zugrunde gehen, wenn diese mit destilliertem Wasser hergestellt sind, nicht aber in peptonhaltigen, auch mit Aq. dest. angesetzten Nährflüssigkeiten. Die minimalen Kupfermengen, welche im destillierten Wasser enthalten 
sind, werden eben durch das Pepton gebunden und können nicht schädlich auf die Zellen wirken.

Bei Konzentrationen, welche zwischen 0,1 und 0,01 in der Mitte liegen, scheint in manchen Fällen die schädliche Wirkung des Kalis schon zu beginnen. So berichtet Dutrochet, dass die Plasmaströmung der Charazellen binnen 35 Minuten aufhöre, wenn man $0,05 \%$ ige Kalilauge einwirken lässt.

Bezüglich der freien Alkali- und Erdalkalibasen lässt sich somit sagen, dass ihre Reaktionsfähigkeit gegen das Plasmaeiweiss nicht sehr gross sei; schon bei $0,01 \%$ Verdünnung wirken sie meist nicht mehr ein. Eine Ausnahme bilden die Typhusbazillen, welche nach Liborius durch $0,0074 \%$ Atzkalk getötet werden.

Die aufquellende Wirkung, welche freie Alkalien auf die Zellen bekanntlich ausüben, treten erst bei höheren Konzentrationen als den hier aufgeführten ein, und zwar längst, nachdem der Tod durch das Alkali vorber bewirkt wurde.

Viel weniger reaktionsfähig als die freien Basen der Alkaligruppen sind natürlich die ebenfalls alkalisch reagierenden Alkalikarbonate.

Viele Bakterienarten gedeihen nur in alkalisch reagierenden Flüssigkeiten; oft enthalten dieselben Kalium- oder Natriumkarbonat bis zu $0,5 \%$. $0,8 \%$ hingegen wird von den Typhusbazillen nicht mehr ertragen, $1 \%$ von den Cholerabazillen nicht (Liborius).

Nach Schröder (Arch. f. exp. Path. 1886) leben Askariden in $5,8 \%$ iger Natriumkarbonatlösung $5-6$ Stunden lang.

O. Loew beobachtete in dem stark alkalisch reagierenden Wasser des Owers Lake, welches unter anderem 2,5\% kohlensauren Natrons enthielt, am Ostabhange der Sierra Nevada in Kalifornien zahlreiche lebende Infusorien, Copepoden, Larven einer gewissen Fliegenart (Ephydra), ferner Schimmelpilze (Petermann's geogr. Mitteilungen 1877).

Ein kräftig alkalisch reagierendes Alkalisalz ist das Dinatriumphosphat.

In einer $1 \%$ igen Lösung dieses Salzes beobachtete ich zunächst keinerlei Veränderung in der Bewegung der zahlreichen vorhandenen Aufgusstierchen. Nach einer Viertelstunde derselbe Befund. Sogar nach 24 Stunden waren noch lebende, normal bewegliche Infusorien sichtbar; einige Individuen (derselben Art!) freilich waren schon abgestorben und manche sogar zerflossen, was jedenfalls auf die durch 
Verdunstung eingetretene Konzentrierung der Lösung zurückgeführt werden kann; man sah am Rand Verdunstungsrückstand, die feuchte Kanmer, in der das Präparat lag, hatte nicht gut geschlossen.

In $10 \%$ iger Lösung sterben die Infusorien sogleich ab unter Zusammenschrumpfen ihres Leibes durch Wasserentzug. Das hat selbstverständlich mit der alkalischen Reaktion nichts zu tun, sondern nur mit der hohen Konzentration der Lösung. Kochsalzlösung von $10 \%$ hat dieselbe augenblickliche Wirkung; die Schrumpfung der Infusorienleiber schien mir eher noch stärker zu sein.

Auch $5 \%$ ige Lösung des Dinatriumphosphates bringt die Infusorien langsam zum Schrumpfen; binnen 5 Minuten hat dann die Bewegung anfgehört. Die Veränderung ist aber keine tödliche. Denn bei Zugabe von Wasser quellen die Tierchen wiederum auf und fangen dann an, lebhaft hin und her zu schwimmen.

2,5\% ige Lösung des Dinatriumphosphates bewirkt zunächst kein Aufhören der Bewegung an den Infusorien, sondern eher eine Beschleunigung; die Tiere scheinen einen Bewegungsanreiz von dieser Lösung zu erhalten. Erst nach einer halben Stunde liessen viele Tiere Stillstand in der Bewegung oder langsame, drehend zuckende Bewegungen erkennen, wobl auch eine Folge der Wasserentziehung.

Bei Auwendung von 2,5\% igem Dikaliumphosphat zeigen sich in wenigen Minuten Schrumpfungserscheinungen an vielen Infusorien, dann Stillstand der Bewegung. Es ist osmotisch wirksamer.

Bezüglich der Dialkaliphosphate können wir also wohl sagen, dass sie keine Verbindungsfähigkeit mit dem Plasmaeiweiss besitzen, und dass sie eine schädliche Wirkung nur bei relativ hoher Konzentration, mindestens $2,5 \%$, hervorzurufen vermögen, und zwar durch Wasserentzug.

Dass aber auch Natriumkarbonat so ungefährlich sei, schien mir - für die mir vorliegenden Infusorien - unwahrscheinlich.

Ich liess also zunächst 2,5\% ige Lösung von $\mathrm{Na}_{2} \mathrm{CO}_{3}$ auf meine Infusorien einwirken und bemerkte eine augenblickliche Abtötung, wenn die Vermischung des infusorienhaltigen Tropfens mit der alkalischen Lösung plötzlich geschah. Statt jedes Infusoriums war dann eine verquollene körnige Masse da.

Lässt man die Sodalösung langsam seitwärts unter dem Deckglas eintreten, so bemerkt man, dass die Infusorien möglichst rasch zurückweichen und eine sehr beträchtliche Steigerung in der Bewegung erfahren; sie eilen wie von einem heftigen Reiz angefacht 
äusserst lebhaft hin und her. Diejenigen aber, welche nicht rechtzeitig entkommen sind, sterben fast momentan $a b$ und verquellen unmittelbar darauf zu einer formlosen körnigen Masse.

Hier ist also eine chemische Verbindung mit dem Plasmaeiweiss wohl anzunehmen; es billet sich eine Natron-Eiweissverbindung, welche lösliche oder stark quellbare Beschaffenbeit besitzt und im Übersehuss der Sodalösung sich rasch auflöst. Von welcher Natur die übrigbleibenden unlöslichen Körnchen sind, wurde nicht festgestellt.

Die von 0. Loew beobachteten Infusorien im Owens Lake müssen von einer viel resistenteren Art gewesen sein, sonst wären sie nicht in dem $2,5 \%$ Natriumkarbonat haltigen Wasser fortgekommen.

Wir haben ja auch oben bei dem Versuch mit I $\%$ iger Natriumphosphatlösung gesehen, dass sogar Individuen derselben Art etwas verschieden sind.

Zwischen Oroanismen verschiedener Gattungen und Arten herrscht bekanutlich oft ein grosser Unterschied hinsichtlich der Widerstandsfähigkeit gegren Gifte.

Hiusichtlich der Wirkungsweise von $0,1 \%$ igen Alkalilösungen, welche ja meist den sofortigen Tod der Zellen herbeifübren, möge nux noch kurz hervorgehoben werden, dass dieselbe eine rein chemische ist. Das Alkali verbindet sich bei dieser Verdünnung noch mit dem Zelleneiweiss und tötet die Zelle natürlich damit ab.

Anflers ist die nicht tödliche. Wirkung noch weit mehr verdunnter Lösungeu der Alkalien und Alkalikarbonate, wenn eine solche überhaupt hervortritt.

Verfasser hat derartige Fälle schon neulich beschrieben (dieses Arch. Bd. 108 1905). Aumouiak und kohlensaures Ammoniak, sogar kohlensaures Kali und Natron, ja auch freies Kali können bei geeigneter hoher Verdünnung "Aggregationserscheinungen" hervorrufen, wohei die Zelle lebend bleibt und nur auf einen Reiz reagiert.

Mit der schwachen Base Koffein kann man bei 0,1\% Konzentration merkwürdiye Veränderungen, z. B. an Amöben, hervorrufen. Koffein wirkt bei $0,1^{\circ}$ o Konzentration auf diese Organismen nicht mehr giftig. Die mikroskopische Beobachtung lehrt vielmehr, dass die Lösung gut vertragen wird. Die freie Ortsbewegung und die strömende Bewegung im Inmern dauern fort, auch bei tagelanger Einwirkung der Lösung; gleichzeitig anwesende sonstige niedere 
Tiere, wie Infusorien, ferner niedere Pflanzen, Schwärmsporen von Algen usw. nehmen ebenfalls keinen merklichen Schaden. Bei längerer Versuchsdauer aber zeigt sich au der lebenden Amöbe eine auffallende Veränderung, indem dieselbe sich nun schärfer von dem ungebenden Wasser abhebt; zahlreiche grosse Vakuolen treten im Innern auf, welche durch stark lichtbrechendes Plasma getrennt sind; die Fortsätze (Pseudopodien) werden länger und dünner, die Bewegung ist langsamer und macht den Eindruck, als ob die sich bewegende Masse nicbt mehr jenen Grad von Dünnflüssigkeit hätte wie zuvor. All das deutet darauf hin, dass das Plasma in einen dichteren (wasserärmeren) Zustand übergegangen ist. Die Vakuolen, offenbar durch Wasserausscheidung aus dem Plasma zustande gekommen, ferner das stärkere Lichtbrechungsvermögen sind bedingt durch den grösseren Eiweissreichtum und geringeren Wassergebalt im Plasma. Es ist der Quellungszustand etwas anders geworden; das Plasma ist substanzreicher geworden und wasserärmer, ohne den lebenden Zustand zu verlieren! Ersetzt man die Koffeinlösung durch reines Wasser, so stellt sich der frühere Zustand der Amöbe wieder her.

Würde in diesem Falle eine chemische Verbindung zwischen Base und Plasmaeiweiss eintreten, so wäre es unmöglich, dass die Amöben nach Tagen noch lebend und beweglich sind. Denn die chemische Reaktion würde naturgemäss fortschreiten müssen; das Koffein würde aus der Lösung (die auch hier in grösserem Überschusse anzuwenden ist) herausgenommen werden und in dem Infusorienleib sich anhäufen; die immer reichlicher sich bildende Verbindung Koffein-Plasmaeiweiss müsste das Absterben der Zelle herbeifübren.

Da das Koffein auch in stärkerem Masse als $0,1 \%$ in Wasser gelöst werden kann (bis $1,3 \%$ ), so ist es nicht schwer, die Probe zu machen, wie sich die Zelle verbalten würde, wenn das Koffein sich mit dem Plasmaeiweiss verbände.

Es gibt übrigens Organismen, die relativ unempfindlich gegen Koffein sind. So sterben manche Spirogyren nicht ab, wenn man sie 24 Stunden lang in kait gesättigter $1,3 \%$ Koffeinlösung liegen lässt.

Ferner sah ich in meiner Flasche mit 1,3\% iger Koffeinlösung zwei allerdings kleine Schimmelräschen wachsen, welche offenbar den geringen vorbandenen Nährstoff trotz der 1,3\% Koffein ausnutzten und davon wuchsen. 
Lässt man 1,3\% ige Koffeinlösung auf Infusorien einwirken, so zeigt sich sehr raseh eine Verminderung in der Bewegungsgeschwintigkeit. Wartet man länger zu, so wird die Bewegung immer langsamer; dabei nimmt der Leib allmählich Kugelgestalt an. Die beliebig fortschreitende Bewegung geht dann in ein Rollen und Drehen an einem engbegrenzten Platz über. Schliesslich tritt Stillstand der Bewegung, dann ein Hervortreiben von blasigen Auswüchsen aus dem Infusorienleib, schliesslich Verquellung ein. Das Koffein scheint hier ähnlich wie ein Alkali zu wirken; eine Trübung des Infusorienleibes durch Bildung eines Eiweissalkaloidniedersehlages konnte ich nicht bemerken.

Dass Koffein auch für Warmblüter ein relativ schwaches Gift ist, sei hier nur kurz erwähnt. Es wirkt auf Gehiru und Rückenmark, später auf periphere Nerven ein, aber beim Menschen z. B. üben Gaben unter $0,3 \mathrm{~g}$ keine nachweisbaren Wirkungen aus; nach $0,36 \mathrm{~g}$ zeigt sich nur eine in einer Stunde vorübergehende Eingenommenheit des Kopfes (nach toxikolog. Handbüchern).

Dass auch andere Gewebe durch Koffeinlösungen verändert werden, geht aus den Beobachtungen Johannsen's hervor, der die Veränderung der quergestreiften Muskulatur von Rana temporaria mikroskopisch verfolgte; sie tritt zuerst an den der Einspritzungsstelle benachbarten Muskeln auf und geht sehr langsam auf immer entfernter liegende Teile über. „Beobachtet man eine Muskelfaser während des Koffeinzusatzes unter dem Mikroskop, so sieht man, wie sich der Inhalt der Muskelzelle bewegt, die Querstreifung verloren geht, die Längsstreifung sehr deutlich wird, die Faser sich fast um die Hälfte verkürzt und an einigen Stellen sich das Sarkolemm abhebt; dasselbe Bild bieten die im lebenden Körper vergifteten Muskeln. Die Muskeln im ganzen erscheinen weiss, blutleer, starr, verkürzt und haben ganz das Aussehen wärmestarrer Muskeln."

Leider kann man aus diesen Angaben nicht ersehen, in welcher Konzentration das Koffein zur Einwirkung auf die Muskelfaser kam. Wabrscheinlich war dieselbe eine ziemlich beträchtliche.

Vielleicht liesse sich auch hier eine ganz andersartige mikroskopische Wirkung erkennen, wenn man das Alkaloid in grosser, nicht mehr tödlicher Verdünnung zur Einwirkung brächte. Es wäre gewiss von grossem Interesse, die Wirkung an lebenden Zellen längere Zeit zu beobachten, wie ich es an Infusorien und Amöben und niederen Pflanzen getan habe. 
Im Anschluss an das Koffein seien nun einige andere organische Basen, besonders die sogenannten Alkaloide kurz besprochen, die zu den interessantesten Giften gehören.

Strychninsalze gelten als intensive Gifte für viele Tiere aus den verschiedensten Abteilungen des Tierreiches; der Grad der Giftigkeit ist aber nach Tiergattungen, Tierindividuen und namentlich nach Art der Zellen verschieden. Wie alle Alkaloide, wirkt das Strychnin in erster Linie auf das Nervengewebe der höheren Tiere ein.

"Man kann sich die Wirkung so denken (0. Loe w a. a. O. S. 85), dass die Basen sich mit den aktiven Proteinstoffen der Zellen verbinden und dadurch eine Störung des Gleichgewichtes im Plasmakörper herbeiführen, was besonders bei Ganglienzellen eine verheerende Wirkung nach sich zieht. Jene Verbindungsfähigkeit ist aber durch verschiedene Faktoren beeinflusst, durch die Konfiguration und den Verdünnungsgrad des Giftes, durch den Labilitätsgrad der Protoplasmaart, durch die Konfiguration der Moleküle der aktiven Proteinstoffe der Zellen und durch die spezifische Tektonik (den mizellaren Aufbau) des Plasmakörpers." "Begünstigt die Konfiguration der Eiweissmoleküle und die Tektonik des Protoplasmas die Anlagerung der Base, so wird selbst bei bedeutender Verdünung des Alkaloides eine Störung im Gleichgewicht des Protoplasmas erfolgen."

Auf tierische Mikroorganismen wirkt Strychnin nicht gerade auffallend giftig ein, bei grosser Verdünnung bleibt die Wirkung ganz aus.

Lässt man Strychninnitrat in $1 \%$ iger Lösung auf Infusorien, Rotatorien usw. wirken, so sterben dieselben binnen einigen Minuten unter körniger Trübung ihres Leibes ab. Das Eindringen des Giftes bietet hier jedenfalls keine grossen Schwierigkeiten, ebenso die Erkennung der chemischen Einwirkung.

Bei Anwendung 0,1\% iger Strychninnitratlösung verstreichen ca. 10 Minuten, bis sämtliche Mikroorganismen bewegungslos sind.

Mit 0,01\% iger Lösung des Strychninsalzes sind nach 1/2 Stunde noch sämtliche Mikroorganismen am Leben und bewegen sich lebhaft umher. Nach 12 stündigem Aufenthalt in der Lösung sind die meisten abgestorben, nur wenige führen noch kreisende oder auch drehende Bewegungen aus.

Man sieht, dass das Strychninnitrat bei grösseren Verdünnungen 
als $1 \%$ nicht unmittelbar tödlich zu wirken vermag, sondern erst nach Ablauf einer durch den Verdünnungsgrad bestimmten mehr oder minder langen Zeit.

Mit Strychnin bildet das Plasmaeiweiss eine unlösliche, in Gestalt von körnigen Ausscheidungen sichtbar werdende chemische Verbindung, welche bei grossen Verdünnungen des Strychnins erst allmählich in solcher Quantität entsteht, dass der Tod die Folge ist.

Um die Grenze der Einwirkung festzustellen, machte ich noch einen Versuch mit $0,001 \%$ iger Strychninnitratlösung.

Nach 36 stündigem Stehen zeigten sich die Tiere völlig unverändert; alle Bewegungen wurden wie gewöhnlich ausgeführt.

Das Strychninsalz war also aus solch verdünnter Lösung nicht aufgesammelt worden, was lediglich darauf zurückzuführen ist, dass eben die Bindung zwischen Strychnin und Plasmaeiweiss bei solcher Verdünnung überbaupt nicht mehr erfolgen kann und somit der chemische Vorgang gar nicht einsetzt.

Die Tatsache der Verbindungsfähigkeit der Alkaloide mit dem Eiweiss wird auch, von Nothnagel und Rossbach (Arzneimittel, S. 652) hervorgehoben.

„Nachdem schon lange bekannt war, dass die Fluoreszenz einer Chininlösung beim Einbringen von Eiweiss schwindet, was auf eine gegenseitige Beeinflussung der Alkaloide und Eiweissstoffe hinweist, unterwarf Rossbach Hühnermuskel und Serumeiweiss der Einwirkung verschiedener Alkaloide und fand, dass alle diese Eiweisslösungen beim Zusammenkommen mit einem Alkaloid in der Wärme in eine gerinnbare und weniger lösliche Modifikation übergeführt werden, indem sich beide Substanzen chemisch miteinander verbinden." Ferner wurde gezeigt, "dass das unter dem Einfluss von Alkaloiden stehende Eiweiss seine Affinität zum erregten Sauerstoff verliert und durch letzteren nicht mehr peptonisiert wird; und endlich, dass das mit Alkaloiden gemischte Eiweiss auch durch Magensaft und Pankreas nicht mehr in Pepton umgewandelt wird. Auch am lebenden Tiere vermochte man nachweisbare Unterschiede in der Löslichkeit der Muskelalbuminate nach Vergiftung mit Veratrin darzutun lauter Tatsachen, die auf chemișche Veränderung des Eiweissmoleküles hinweisen."

Auch wenn man essigsaures Chinin in $0,1 \%$ iger Lösun: auf die Infusorien einwirken lässt, hat man den Eindruck, als finde eine Verbindung mit dem Plasmaeiweiss statt. Zwar sterben die 
Nochmals über die Wirkung stark verd. Lösungen auf lebende Zellen. 193

Infusorien nicht augenblicklich ab. Aber nach etwa füf Minuten findet man dieselben im abgestorbenen Zustande wieder, mit starker, körniger Trübung ihres Körpers.

Wendet man 0,01\% ige Lösung des essigsauren Chinin an, so bleiben die Infusorien am Leben; sogar nach 24 Stunden siebt man noch lebende Infusorien.

Penicilliumsporen keimen nicht in einer $10 \%$ igen Rohrzuckerlösung, welcher $0,25 \%$ salzsaures Chinin zugesetzt ist (Manassein).

In $0,1 \%$ iger Lösung von salzsaurem Nikotin sterben die Infusorien zunächst nicht ab. Auch nach Ablauf einer halben Stunde ist noch keine Veränderung zu bemerken. Dagegen zeigt sich nach 24 Stunden kein einziges lebendes Infusorium mehr.

In $0,01 \%$ iger Lösung waren sogar nach 24 Stunden noch sämtliche Infusorien unverändert. Sie hatten sich nur dem Rande des Deckglases genähert und waren zum Teil in noch ausserhalb des Deckglases befindliche Flüssigkeit übergetreten, wahrscheinlich um Sauerstoff zu bekommen.

M o r phi u mazetat zeigte sich noch weniger schädlich für niedere Tiere. In $0,1 \%$ iger Lösung blieben Paramäcien 6 , ja sogar 48 Stunden lang am Leben, desgleichen Insektenlarven. Diatomeen aber schienen ihre Beweglichkeit verloren zu haben. Kladophoren und Vaucherien waren zum Teil abgestorben.

Die Verbindungsfähigkeit der Alkaloide mit dem Plasmaeiweiss hört also bei niederen Organismen schon in relativ geringen Verdünnungen auf.

$\mathrm{Zu}$ den Stoffen, welche durch chemische Verbindung mit dem Plasmaeiweiss giftig wirken, gebört vielleicht auch die Blausäure oder Cyanwasserstoffsäure.

Als ich eine von Kahlbaum (Berlin) bezogene, als $12 \% \mathrm{ig}$ bezeichnete Cyanwasserstoffsäure nach längerer Zeit betrachtete, zeigte sich in der Flüssigkeit Schimmel!

In dieser Flüssigkeit blieben Infusorien zunächst völlig unverändert, ebenso natürlich in einer aufs Zehnfache verdünnten Lösung:

Sogar nach 24 Stunden zeigten die Infusorien in beiden Lösungen noch keinerlei Veränderung!

Es kann kein Zweifel darüber bestehen, dass die Blausäurelösung durch langes Stehen chemisch verändert war und somit nicht mehr wirken kounte. 
Denn wenn auch die Blausäure für niedere Organismen bę weitem kein so starkes Gift ist wie für höhere Tiere, so ist doch nachgewiesen worden, dass Infusorien durch $0,1 \%$ ige Lösung bald absterben, während Algen noch einige Zeit am Leben bleiben (O. Loew). Meine eigenen Versuche mit frisch bezogener Blausäure ergaben, dass $1 \%$ die Paramäcien augenblicklich tötet, $0,1 \%_{0}$ aber binnen fünf Minuten nicht merklich verändert; auch nach vier Tagen waren viele in $0,1 \%$ noch lebend. Blausäure tötet bei Verdünnung 1:430 das Protoplasma der Drosera-Tentakel (Darwin). Bei einer gewissen Verdünnung wirkt sie lähmend auf die Gärtätigkeit der Bierhefe, ohne das Leben dieser Zellen zu vernichten; nach Entfernung der Säure kann die Gärtätigkeit wieder beginnen. Würmer bleiben in $0,1 \%$ igen Blausäurelösungen längere Zeit am Leben (0. Loew, a. a. O. S. כّ4). Schröder sah Askariden (Spulwürmer) in einer $3 \%$ igen Lösung des fast ebenso giftigen Cyankalium (blausauren Kaliums) erst nach $1^{1 / 4}$ Stunden sterben (Arch. f. exp. Path. Bd. 19, 290). Ein Myriapode, zur Gattung Fontaria gehörend, produziert sogar Blausäure, wenn er gereizt wird (Egeling, Pflüger's Arch. Bd,28, 576).

Aus all diesen Beobachtungen geht jedenfalls hervor, dass die Blausäure nicht zu denjenigen Giften gehört, welche sich durch sebr grosse Reaktionsfähigkeit (Verbindungsfähigkeit) auszeichnen.

Um so auffallender ist die bekannte enorme Giftwirkung bei höheren Tieren und den Menschen.

Nach Gréhant genügt $1 / 90000 \mathrm{HCN}$ vom Gewichte des Blutes. eines Hundes, um diesen in wenigen Augenblicken zu töten. Erwachsene Menschen und grössere Tiere können schon durch $0,06 \mathrm{~g}$, also einen Tropfen wasserfreier Blausäure getötet werden. Kaltblüter (Frösche, Fische) erliegen langsamer als die Warmblüter. Kleinen Vögeln, Meerschweinchen usw. braucht man nur eine Spur Blausäure vor die Nasenöffnung zu bringen und dieselbe eine Sekunde einatmen zu lassen, um sogleich Vergiftungserscheinungen und nach 15 Sekunden den Tod zu bewirken; Gänse, Enten sterben von wenigen Zehntelmilligramm Blausäureanhydrid innerhalb einer Minute.

Daraus ist nun freilich nicht zu entnehmen, in welcher Verdünnung die Blausäure auf die dagegen empfindlichen Organe, Gehirn und Rückenmark, zur Einwirkung gelangt. Jedenfalls wird sich dieselbe im Blute auflösen, ob sie nun in die Blutbahn eingespritzt oder durch die Lungenkapillaren bein Atmen aufgenommen 
Nochmals über die Wirkung stark verd. Lösungen auf lebende Zellen. 195

wurde, und mit diesem zu den Zentralorganen der Empfindung gelangen, wo sie dann die Giftwirkung erst äussert; denn wenn man (lie Blutgefässe unterbindet und damit die Weiterbeförderung des Giftes verhindert, unterbleibt Vergiftung und Tod (Nothnagel und Rossbach, Arzneimittellehre, S. 644). Wie weit sich nun die Blausäure in den 15 Sekunden, die der Blutstrom zu einem Körper. umlauf nötig hat, mit diesem vermischt, in welcher Verdünnung sie also bei den Zentralorganen anlangt, lässt sich wohl nicht berechnen. Jedenfalls wird diese Verdünnung eine sehr bedeutende sein, wenn z. B. einem grösseren Warmblüter nur $0,06 \mathrm{~g}$ Blausäure eingespritzt wurden. Nehmen wir an, die Blausäure babe sich während des Umiaufes bis auf einen Liter verdünnt, so hätten wir eine etwa 0,006\% ige Lösung, welche also die Blausäure auf ungefähr $1: 20000$ verdünnt enthält.

Solche Lösungen wirken auf niedere Tiere und Pflanzen absolut nicht mehr.

Nach O. Loew kann man die Wirkung der Blausäure mit ihrer Fähigkeit, in Aldehydgruppen einzugreifen, in Beziehung- bringen. „Bei gewisser Verdünnung wird sie nur noch in Aldehydgruppen labilster Art eingreifen, erst bei stärkerer Konzentration in alle. Ist nun das aktive Protein der Ganglienzellen labiler als das anderer Zellen, so begreift man, dass Spuren von Blausäure, welche anderen Zellen nichts mehr schaden, doch noch die labilsten Ganglienzellen momentan angreifen können."

Nach Herrmann wirkt die Blausäure auf nervöse Zentralorgane und hemmt die respiratorischen Vorgänge in den Geweben, welche besonders von den Warmblütern keinen Augenblick entbehrt werden können.

Somit ist anzunehmen, dass die Blausäure bei dem Transport durch den Körper zunächst nirgends verbraucht wird und weder mit dem Plasma der Blutkörperchen noch mit dem angrenzenden Gewebe sich verbindet. Erst gewisse zentrale Nervengewebe sind imstande, diese Bindung zu vollziehen; sie sterben dadurch ab und machen damit den ganzen Körper des Tieres unfähig, weiter zu leben.

Die Blutzellen usw. möchten demnach in ihrer geringen Empfindlichkeit gegen die Blausäure mit den Zellen der niederen Tiere und der Pflanzen vergleichbar sein.

Würden dieselben die Blausäure chemisch binden und damit absterben, so würde hierdurch die geringe Blausäuremenge baldigst 
unsehädlich gemacht sein und nicht bis zu den zentralen Nervenorganen vordringen; das Absterben einer Anzahl Blutkörperchen würde wohl keine schweren Folgen haben.

Von dem als Desinfektionsmittel so geschätzten Formaldehyd lässt sich wohl mit Bestimmtheit annehmen, dass er auch durch chemische Verbindung mit dem Plasmaeiweiss schädlich wirkt (siehe unten).

Formaldehyd von $1 \%$ tötet die Infusorien momentan, ebenso solcher von $0,1 \% ; 0,01 \%$ tötet binnen $5-10$ Minuten; zuerst schwimmen die Tiere lebhaft umher, erst allmählich verlangsamt sich die Bewegung, schliesslich tritt Stillstand ein.

In $0,001 \%$ iger Lösung bewegen sich die Infusorien zunächst äusserst lebhaft, als wollten sie entfliehen; sie sterben darin aber nicht binnen 24 Stunden ab, sondern zeigen sich dann anscheinend unverändert; sogar nach drei Tagen sind sie noch am Leben und normal beweglich.

Durch $0,0001 \%$ iger Lösung werden die Infusorien natürlich noch weniger angegriffen. Nach 24 Stunden oder sogar nach vier Tagen zeigt sich keine Spur von schärlicher Einwirkung.

Die Empfindlichkeit der Fäulnisbakterien ist eine ähnliche wie die bei den Infusorien beobachtete.

Die Gegenwart einer 0,001\% entsprechenden Menge von Formallehyd reicht nach meinen Versuchen nicht aus, um die Fäulnis einer 1/2\% \% igen, auch mit mineralischen Nährstoffen versehenen Peptonlösung zu verhindern; nach drei Tagen hat sich schon Fäulnis eingestellt. Bei der. Verdünnung 1:50000 hört der Formaldehyd auf, giftig für die Pilze zu sein; durch stärkere Konzentrationen wird Fäulnis verhindert.

Nur dann, wenn man neben Formaldehyd Salmiak darbietet, der von vielen Pilzen als Stickstoffquelle verwendet werden kann, ist der erstere noch bei Konzentrationen bis zu 1:5000 unschädlich, ja er dient dann sogar als Nährstoff.

Drei Formaldehydlösungen: a) $1: 20000$, b) $1: 10000$, c) $1: 5000$ zeigten, als sie mit Salmiak als einziger Stickstoffquelle (ausserdem Phosphaten usw.) versetzt wurden, binnen acht Tagen deutliche Pilztrübung, welche bei Lösung $1: 5000$ allmählich stärker wurde und zu einem erheblichen Absatz von Bakterienmasse führte. Nach o. Loew tritt in solchen salmiakhaltigen Lösungen die Bildung von Hexamethylentetramin ein, welch letzteres dann ernährt. 
Wenn der Formaldehyd aber eine solche Bindung nicht erfährt, dann wirkt er in der Verdünnung 1:5000 unfehlbar tödlich auf lebende Zellen; auch $0,01 \%$ ist noch unbedingt wirksam.

Nach H. Buchner, Trillat Aronson wirkt er auch stark giftig auf pathogene Bazillen. Typhusbazillen werden noch bei einer Verdünnung des Formaldehydes von 1:20000 getötet und noch bei $1: 100000$ in ibrer Entwicklung geschwächt.

Asseln, Würmer, Vollusken werden nach 0 . Loew durch $0,05 \%$ igen Formaldehyd binnen zwei Stunden getötet.

Wir sehen also, dass der Formaldehyd noch bei beträchtlichen Verdünnungen mit dem Plasmaeiweiss reagiert, aber in diesem Punkte bei weitem nicht an Sublimat und Höllenstein heranreicht.

Nach O. L o e w muss man sich die Einwirkung so denken, dass die Aldehydgruppe in die Amidogruppen des Plasmaeiweisses eingreift und stickstoffhaltige Derivate bildet, etwa wie Anilin mit Formaldehyd reagiert:

$$
\underbrace{\mathrm{C}_{6} \mathrm{H}_{5} \mathrm{NH}_{2}}_{\text {Anilin }}+\mathrm{CH}_{2} \mathrm{O}=\mathrm{C}_{6} \mathrm{H}_{5} \mathrm{~N}: \mathrm{CH}_{2}+\mathrm{H}_{2} \mathrm{O} \text {. }
$$

„Man kann sich leicht davon überzeugen, dass schon in den passiven Eiweissstoffen ein Teil des Stickstoffes in Form von Amidogruppen $\left(\mathrm{NH}_{2}\right)$ vorhanden ist; denn beim Behandeln (z. B. des Peptons) mit salpetriger Säure entweicht viel Stickstoffgas, was nicht der Fall wäre, wenn sämtlicher Stickstoff sekundär oder tertiär gebunden wäre. Was zunächst den Formaldehyd betrifft, so zeichnet er sich schon dadurch aus, dass er mit Propepton und, bei Anwesenheit von etwas Salzsäure, auch mit Eiweiss sehr schwer lösliche Verbindungen liefert. Je labiler die Amidogruppen sind, desto energischer wird der Formaldehyd eingreifen!"

Dass auch andere Aldehyde als der Formaldehyd energisch auf das lebende Plasma wirken, geht aus folgenden Versuchen hervor:

Durch Paraldehyd von 0,002\% \% iger Verdünnung werden Algen. binnen 24 Stunden getötet.

Oxy benzald ehyd stellt als Paraverbindung ein weisses Pulver, als Orthoverbindung eine Flüssigkeit von ziemlich starkem bittermandelähnlichen Geruche dar. Die $0,1 \%$ igen Lösungen der beiden Substanzen wirken schädlich auf Algen ein, aber die Orthoverbindung mehr als die Paraverbindung. Auch bei Fäulnisbakterien machte sich ein ähnlicber Unterschied geltend. Denn in einer $0,02 \%$ igen Lösung der Orthoverbindung trat (binnen 14 Tagen) keine Fäulnis 
ein, während bei Gegenwart von 0,02\% Paraoxybenzaldehyd in einer fäulnisfähigen Nährlösun̊̆ binnen wenigen Tagen Fäulnis eintritt. Dadureb, dass in der Orthoverbindung die Aldehydgruppe mit der Hydroxylgruppe unmittelbar benachbart ist, wird offenbar eine grössere Reagierfühigkeit und damit eine grössere Giftigkeit herbeigeführt. Es ist das ein weiterer Beleg dafür, dass die chemische Konstitution massgebend ist für den Giftigkeitsgrad einer organischen Substanz; zwei sonst ganz gleich zusammengesetzte Körper, die nur durch die Ortho- und Parastellung der Hydroxylgruppe zur Aldehydgruppe sich unterscheiden, verhalten sich verschieden in der giftigen Beschaffenheit. Erst wenn man den Orthooxybenzaldehyd auf $0,005 \%$ verdünnt, bört die Giftwirkung auf; bei so geringer Menge dieses Giftes tritt die Fäulnis einer Peptonlösung nach einigen Tagen ein.

Dass es in erster Linie die Aldehydgruppe ist, welche die starke Giftigkeit des 0-Oxybenzaldehydes herbeiführt, geht aus dem Verhalten der Oxybenzoesäure (mit Kali neutralisiert) hervor. Dieselbe vermag weder als 0 - noch als $\mathrm{p}$-Verbindung bei einer Konzentration von $0,02 \%$ die Fäulnis einer mit den nötigen Mineralstoffen versetzten Peptonlösung zu verhindern. Sogar 0,05\% der Oxybenzoesäure ist nicht imstande, die Entwicklung von Fäulnisbakterien in einer Peptonlösung zu verhindern.

Auch Äthylaldehyd ist ein nicht unbeträchtliches Gift für niedere Organismen. So starben in einer $0,02 \%$ igen Auflösung desselben Vaucherien und Conferven binnen 24 Stunden ab; Spirogyren und Cladophoren scheinen etwas resistenter zu sein. Um zu sehen, wie sich Fänlnispilze dagegen verhalten, stellte ich mir $1 / 2 \%$ ige Peptonlösungen her (mit Zusatz von etwas Dikaliumphosphat und Magnesiumsulfat) und fügte denselben Äthylaldehyd zu, das eine Mal so viel, dass die Verdünnung $0,1 \%$ entstand, das andere Mal $0,02 \%$. In ersterem Falle trat keine Fäulnis ein; die Flüssigkeit war nach vier Tagen vollkommen klar und liess keinen Geruch erkennen als den des Äthylaldehydes. Im zweiten Falle stellte sich binnen drei Tagen stinkende Fäulnis ein. Während also die Verdünnung $0,1 \%$ noch lebensfeindlich für Fäulnisbakterien ist, lässt $0,02 \%$ Äthylaldehyd diese Spaltpilze aufkommen. Fäulnispilze sind also nicht in sehr bohem Masse empfindlich gegen Äthylaldebyd, etwas weniger als die Algen Cladophora, Vaucheria, Conferva.

Übrigens kann der Äthylaldehyd bei geeigneter grosser Verdünnung sogar als Nährstoff (Kohlenstoffquelle) für Pilze dienen, wie 
folgende Versuche zeigen : Es wurden drei Lösungen bereitet: a) $0,1 \%$, b) $0,02 \%$, c) $0,01 \%$. Alle drei Lösungen wurden mit den nötigen Mineralstoffen ${ }^{1}$ ) versehen und mit pilzhaltiger Flüssigkeit geimpft. Bei a war nach 14 Tagen noch keinerlei Pilzbildung zu bemerken; nach drei Wochen zeigten sich Schimmelflocken (Penicillium); die Flüssigkeit reagierte nun schwach sauer; nach einer weiteren Woche war ein mächtiger Bodensatz da, bestehend aus Penicillium. Wabrscheinlich war zuerst eine Oxydation zu Essigsäure eingetreten und hatten sich die Schimmelpilze von dieser ernährt. Bakterien traten nicht auf. In Lösung b zeigten sich scbon nach 12 Tagen Fadenpilze (Penicillium), welche in der Flüssigkeit schwammen und an deu Wänden festsassen; ausser Penicillium waren hier aber auch zallreiche Spaltpilze anwesend. In Lösung $\mathrm{c}$ trat nach neun Tagen eine Trübung auf, herrührend von Bakterien, welche binnen weiteren zwei Tagen sebr stark wurde. Eine Plattenkultur der in der Flüssigkeit $\mathrm{c}$ befindlichen Pilze ergab zweierlei Spaltpilze; erstens solche, die Gelatine verflüssigen und wolkig am Boden der Platte liegen, zweitens solche, welche Gelatine nicht verflüssigen, rundlichen bis ovalen Umriss haben und von schwach gelblich-brauner Farbe sind. Beide bestanden aus Kurzstäbchen, in letzterem Falle aus sehr lebhaft beweglichen.

Dass ein organischer Stoff bei $0,1 \%$ und stärkerer Konzentration ein Gift, bei $0,01 \%$ eine Kohlenstoffquelle für Pilze sein kann, ist eine ebenso interessante als häufig konstatierte Tatsache.

Die Giftwirkung des Aldehydes bei stärkerer Konzentration ist, wie oben auseinandergesetzt, durch direkte chemische Verbindung der Aldehydgruppe mit den (labilen) Amidogruppen des Plasmaeiweisses zu erklären. Dass bei $0,01 \%$ keine giftige Wirkung mehr auftritt, ist ganz ohne Zwang darauf zurückzuführen, dass eben bei dieser Konzentration die chemische Reaktion zwischen Aldehydgruppe im Aldehyd und Amidogruppe im Eiweiss nicht mehr eintritt.

Wie aber kommt die ernährende Wirkung zustande?

Bei der Ernährung werden aus dem Äthylaldehyd Kohlehydrate und (unter Zutritt stickstoffhaltiger Substanzen) Eiweissstoffe gebildet - ein Vorgang, der ganz obne Beispiel in der Chemie dasteht.

Offenbar bewirkt das Protoplasma durch blossen Kontakt eine so weit gehende Veränderung, die gerade zu dem führt, was die

1) Ca-Nitrat als N-Quelle, Dikaliphosphat, Magnesiumsulfat. 
lebende Zelle zin ihrem Bestande und zur Vermehrung braucht (Eiweiss und Kohlehydrat). Eine chemische Umsetzung, in die das Plasmaeiweiss eintritt, ist hier natürlich ausgeschlossen; sonst würde ja der Tod die unvermeidliche Folge sein. Die Ernährung ist wohl eine jener rätselhaften Kontaktwirkungen, bei denen die Kontaktsubstanz selbst unverändert und unbegrenzt wirksam bleibt.

Weitere Substanzen, die hier interessieren, sind das Hydroxylamin und das Phenylhydrazin. Viktor Meyer hat bei ersterem, Emil Fischer bei letzterem gezeigt, dass alle Aldehyde selbst bei grossen Verdünnungen darauf reagieren, wobei unter Wasserabspaltung die Aldehydgruppe als solche verloren geht und Produkte entstehen, welche (wie der ursprüngliche Aldehyd) auch noch silberabscheidende Kraft besitzen ( $O$. Loew, in Pflüger's Arch. 1885 S. 517).

$$
\mathrm{R}-\mathrm{C}<_{\mathrm{H}}^{\mathrm{O}}+\mathrm{N}-_{\mathrm{H}}^{-\mathrm{OH}}=\mathrm{R}-\mathrm{C}_{\mathrm{H}}^{\mathrm{N}-\mathrm{OH}}+\mathrm{H}_{2} \mathrm{O}
$$

Ein be- Hydroxyl- Ein Aldoxim. liebiges Aldehyd. amin.

$$
\mathrm{R}-\mathrm{C}_{\mathrm{H}}^{\mathrm{O}}+\mathrm{NH}_{2}-\mathrm{NH}-\mathrm{C}_{6} \mathrm{H}_{5}=\mathrm{R}-\mathrm{C}_{\mathrm{H}}^{\mathrm{N}-\mathrm{NH}-\mathrm{C}_{6} \mathrm{H}_{5}}+\mathrm{H}_{9} \mathrm{O}
$$

Phenylhydrazin. Ein Aldehydrazin.

Da nun das aktive Eiweiss des Zellplasmas wahrscheinlich Aldehydnatur besitzt, wie Loew und Verf. seinerzeit darzulegen versuchten, so ist zu erwarten, dass die genannten Stoffe durch chemische Verbindungsfähigkeit auf das Plasma recht giftig wirken werden.

Die Versucbe 0. Loew's haben dies bestätigt.

Da uns hier hauptsächlich die Verdünnungsgrade interessieren, bei denen die Verbindung noch eintritt, so seien aus den Resultaten Loew's nur einzelne herausgegriffen.

Maiskeimlinge wurden vergleichsweise in Lösungen von salzsaurem Hydroxylamin 1: 15000 und Salmiak $1: 15000$ gesetzt. Nach 8 Tagen waren bei den Salmiakpflänzchen die Wurzeln bereits um das Vierfache gewachsen, bei den Hydroxylaminpflanzen kaum um ein Zehntel; letztere blieben bald ganz stationär. Die Länge der oberirdischen Teile betrug nach 14 Tagen bei den Salmiakpflänzchen 9-10 cm, bei den Hydroxylaminpflänzehen, welche allmählich dahinsiechten, erreichten sie nur $2-5 \mathrm{~cm}$. Als nun die vollkommen gesund aussehenden Salmiakpflänzchen in eine nit 
Nochmals über die Wirkung stark verd. Lösungen auf lebende Zellen. 201

Brunnenwasser hergestellte Nährlösung, welche $0,10 \% \quad \mathrm{~K}_{2} \mathrm{HPO}_{4}$, $0,05 \%\left(\mathrm{NO}_{3}\right)_{2} \mathrm{Ca}, 0,05 \% \mathrm{MgSO}_{4}$ und $0,01 \%$ salzsaures Hydro$x y l a m$ in enthielt, versetzt wurden, starben sie schon nach $z$ wei Tagen vollständig ab, Blätter und Stengel verloren den Turgor und vertrockneten.

Mit Helianthuskeimlingen wurden ganz ähnliche Erfahrungen gemacht; das Wachstum der Wurzel in der so stark verdünnten Lösung $(1: 15000)$ des salzsauren Hydroxylamins blieb bald gänzlich aus, der Stengel entwickelte sich aber noch einige Zeit lang, kränkelte dann und vertrocknete.

In fäulnisfähiger Lösung unterbleibt die Fäulnis, wenn nnan $0,01 \%$ salzsaures Hydroxylamin zusetzt (trotz wiederholter Infektion). Also wird durch das Gift in dieser Verdünnung die Entwicklung der Fäulnisbazillen verhindert.

Interessant ist ein Vergleich mit Alkaloiden, den O. Loew anstellte.

7 Kolben wurden aufgestellt. In jeden kam die gleiche Nährlösung, nämlich: Wasser $100 \mathrm{ccm}$, weinsaures Ammoniak 0,5 g, Monokaliumphosphat $0,4 \mathrm{~g}$, schwefelsaure Magnesia $0,1 \mathrm{~g}$.

Kolben Nr. 1 erhielt keinen weiteren Zusatz,

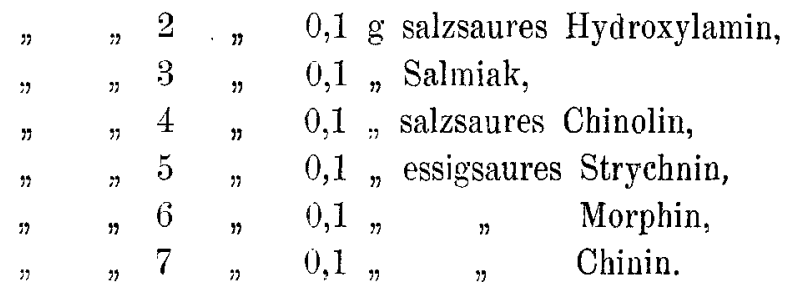

„Sämtliche Lösungen reagierten schwach sauer. Sie wurden mit Bakterien und Schimmelsporen infiziert und 8 Wochen bei gewöhnlicher Temperatur stehen gelassen. Beim Hydroxylamin hatte sich trotz mehrmals wiederholter Infektion keine Spur von Schimmel oder Bakterien entwickelt, die Lösung war vollständig intakt geblieben. Beim Chinolin hatte sich etwas Schimmel, aber keine Spur Bakterien entwickelt; aber bei allen übrigen. Flüssigkeiten war nach anfänglicher Schimmelbildung bald eine starke Bakterienvegetation aufgetreten, und die Reaktion war in eine alkalische übergegangen infolge der Umwandlung des weinsauren Ammoniaks in kohlensaures; nur bei der Hydroxylamin- und der Chinolinmischung war die ursprüngliche saure Reaktion noch erhalten." 
Diatomeen, Infusorien, Wasserasseln, Egel, Planarien, Schnecken (Limnaea, diese erst nach 45 Stunden) werden durch salzsaures Hydroxylamin in der Verdünnung $0,01 \%$ getötet.

Selbst durch $0,001 \%$ werden Diatomeen getötet, Infusorien aber und Ostracoden leben weiter (selbst nach drei Tagen noch). Durch $0,005 \%$ aber werden auch die Infusorien abgetötet.

Hunde werden nach Raimundi und Bertoni dureh Dosen von $0,5 \mathrm{~g}$, Frösche durch $0,002-0,005 \mathrm{~g}$ Hydroxylamin getötet.

Dasselbe gehört also zu den stärkeren Giften; es wirkt ferner auf alle Organismen giftig ein.

In salzsaurem Phenylhydrazin von 1:50000 sterben nach O. Lo e w viele niedere Organismen (Diatomeen, Oscillarien, Rotatorien, Infusorien) binnen zwei Tagen ab.

$0,05 \%$ salzsaures Phenylhydrazin hindert nach demselben Forscher die Entwicklung von Pilzen in guten Nälırlösungen.

O. Loew stellte auch durch Vergleiche fest, dass Hydroxylamin $\left(\mathrm{NH}_{2} \cdot \mathrm{OH}\right)$ ein stärkeres Gift sei als Ammoniak $\left(\mathrm{NH}_{3}\right)$; Phenylhydrazin $\left(\mathrm{C}_{6} \mathrm{H}_{5}-\mathrm{NH}-\mathrm{NH}_{2}\right)$ ein stärkeres als Anilin $\left(\mathrm{C}_{6} \mathrm{H}_{5} \cdot \mathrm{NH}_{2}\right)$. "Diese Tatsachen sprechen für die Aldehydnatur des aktiven Albumins."

Hinsichtlich der Schwermetallsalze wurde schon neulich hervorgehoben (dieses Archiv Bd. 108 1905), dass dieselben oft eine erstaunliche Reaktionsfähigkeit gegen das Plasmaeiweiss besitzen.

Die Einwirkung stellt sich O. Loew folgendermassen vor: "Wenn Amidosäuren mit Salzen von Schwermetallen behandelt werden, so kann entweder Wasserstoff in der Carboxylgruppe orler in der Amidogruppe durch das Metall ersetzt werden. Auch bei Harnstoffderivaten und manchen Basen ist der Wasserstoff der Amidogruppe durch Metalle ersetzbar. In komplizierten Verbindungen, wie den Proteinstoffen, wird an Stickstoff und an Sauerstoff gebundener Wasserstoff ersetzbar sein. Manche Metalle, wie Silber und Quecksilber, ersetzen sogar mit Vorliebe den Wasserstoff der Amidogruppen. Vielleicht beruht es gerade hierauf, dass die Salze des Silbers und Quecksilbers durch besondere Giftigkeit sich auszeichnen. Dass auch Quecksilberdiphenyl und sogar metallisches Quecksillber (wenn in Dunstform eingeatmet) giftig wirken, beruht auf der Umwandlung in salzartige Verbindungen im tierischen Körper. Ein Liter Luft kann bei $20^{\circ} 0,7 \mathrm{mg}$ Hg-Dampf aufnehmen." 
Nochmals über die Wirkung stark verd. Lösungen auf lebende Zellen. 203

Es seien hier noch einige vergleichende Versuche über die Wirkung der Schwermetallsalze, alle an ein und derselben Infusorienart angestellt, nachgetragen, um zu zeigen, dass die Quecksilber- und Silbersalze auch hier so sehr von den anderen Sehwermetallsalzen sich unterscheiden.

$0,1 \%$ ige Lösung von salpetersaurem Quecksilberoxyd tötet dje Infusorien momentan ab unter starker Trübung mit mikroskopisch noch sichtbarer Rötlich-gelb-Färbung.

Auch in $0,01 \%$ iger Lösung stellen die Infusorien augenblicklich ihre Bewegungen ein; man kann gar nicht rasch genug beobachten, um den Übergang zu bemerken. Durch Behandlung mit Schwefelwasserstoff-Wasser kanı man dann die Infusorien dunkel färben.

Sogar in 0,001\% iger Lösung wird die Bewegung der zuvor äusserst lebhaft durcheinanderwimmelnden Infusorien fast augenblicklich langsamer; binnen wenigen Minuten tritt dann bei vielen Individuen absolute Unbeweglichkeit und Trübung ein.

Wie ausserordentlich energisch reagiert somit das Quecksilbersalz mit dem Plasmaeiweiss!

Übrigens ist mit $0,001 \%$ sicher noch nicht die Grenze der Reaktionsfähigkeit erreicht, sonst würde die Wirkung nicht so rasch eintreten.

Wegen früherer Untersuchungen in dieser Sache wurde das Reaktionsvermögen hier nicht weiter verfolgt.

Erwähnt sei nur noch, dass Sublimat von 1: 100000 die Fäulnis von fäulnisfähigen Flüssigkeiten verbindert, solches von $1: 500000$ aber nicht mehr; und dass nach R. Koch Sublimat von 1:300000 die Auskeimung der Milzbrandsporen hindert.

Dass Spirogyren durch Sublimat von 1:100 Millionen noch geschädigt werden, wurde schon mitgeteilt.

Ebenso auch beim salpetersauren Silber, von dem nur festgestellt wurde, dass $0,1 \%$ ige Lösung die Infusorien augenblicklich tötet, wie auch $0,01 \%$ ige und sogar 0,001\% ige Auflösung! An den Infusorien der $0,001 \%$ igen Lösung trat dann mit Schwefelwasserstoffwasser eine starke Bräunlichfärbung ein, während die Lösung selbst unter dem Mikroskop farblos blieb. Die Fäulnis wird noch durch Silbernitrat von 1:500000 hintangehalten.

Gegen Kupfervitrol sind merkwürdigerweise manche Pilzzellen ziemlich wenig empfindlich, während Algen äusserst leicht geschädigt werden, ebenso Infusorien. 
Verfasser hat über erstere in Pharm. C.-H. 30. Apr. 1903 einige Angaben gemacht:

„Hefe, welche fünf Tage lang in 0,1\% \% iger Kupfervitriollösung (50 g Hefe auf $500 \mathrm{ccm}$ Lösung) gelegen hatte, zeigte unter dem Mikroskop noch kein durehaus verändertes Aussehen; in vielen Hefezellen allerdings war der Inhalt kontrahiert. Es musste ein Teil der Hefezellen abgestorben sein, weil schon am dritten Tage ron unten her eine bräunliche Färbung in der Flüssigkeit aufgetreten war, was auf ein Austreten von färbenden Substanzen aus den Hefezellen gedeptet werden muss.

Das Gärvermögen war nach fünf Tagen noch erhalten. Es wurde sowohl Rohrzucker als auch reiner Malzzucker kräftig vergoren. Demnach sind auch die Enzyme Invertin und Glukase noch aktiv gewesen.

Nach zehn Tagen zeigte sich eine Haut auf der Kupfervitriollösung, welche aus lauter kleinen Hefezellen, die lebbaft sprossten, bestand.

Es gibt somit eine Hefeart, welche bei Gegenwart von $0,1 \%$ Kupfervitriol wächst und assimiliert. Das assimilierende Plasma und das Vermehrungsplasma werden also durch $0,1 \%$ Kupfervitriol nicht. abgetötet - binnen zehn Tagen.

In $0,05 \%$ iger Kupfervitriollösung bildete sich binnen gleicher Zeit eine Haut, welche aus Bakterien bestand, die Hefezellen umsponnen hielten.

In $0,02 \%$ iger Kupfervitriollösung entstand schon binnen sechs Tagen eine Pilzhaut; auch war die Flüssigkeit trüb von Bakterien.

Ersterer Rasen $(10,2 \mathrm{~g})$ war nach dem Abtrocknen stark grün auf der unteren Seite, hatte also Kupfersalz an sich (basisches Kupferkarbonat?) - Dasselbe löste sich in Salzsäure unter Gasentwicklung auf).

Als diese rom Schimmel befreiten Lösungen noch weiter stehen blieben, bildete sich von neuem eine Schimmeldecke.

Es besitzen somit einzelne Organismen gegen dieses sonst so starke Gift eine sehr erhebliche Resistenz.

Assimilation, Wachstum und Zellteilung finden bei jenem Schimmelpilz sogar noch bei Gegenwart von 1\% Kupfervitriol statt."

Wenn man Kupfervitriol auf $0,1 \%$ verdünnt und in diese Lösung die oft genannte Infusorienart Paraniäcium hineinbringt, so sterben sie augenblicklich unter Trübung $a b$. 
Nochmals über die Wirkung stark verd. Lösungen auf lebende Zellen. 205

In $0,01 \%$ iger Lösung leben die widerstandsfäbigeren nur noch einige Minuten weiter, dann stellen sie für immer ihre Bewegung ein. So rasch findet hier eine Aufspeicherung des Kupfers statt.

Man kann diese auch direkt sichtbar machen durch Anwendung von Schwefelwasserstoffwasser, worin die Infusorienleiber eine dunkle Farbe annehmen.

Dass gegen Kupfervitriol viele Organismen noch bei weit grösserer Verdünnung empfindlich sind, wurde schon hervorgehoben. Kupfervitriol von $1: 50000$ tötet binnen zwei Tagen die Fadenalgen Cladophora, Conferva, Spirogyra, Vaucheria, ferner Infusorien, Rädertierchen, Würmer, Insektenlarven. Auch in Lösung $1: 200000$ sterben diese Organismen $a b$, wenn man genug Lösung und wenig Versuchszellen anwendet.

Spirogyren sind in ihren Chlorophyllapparaten so empfindlich gegen Kupfervitriol, dass in Lösung 1:100 Millionen schon nach 24 Stunden Absterbeerscheinungen sichtbar werden.

Fäulnis wird dureh 1:100000 verhindert, nicht aber durch $1: 500000$.

Mit $0,1 \%$ iger Goldchloridlösung hört die Bewegung der Infusorien augenblicklich auf; dieselben sterben unter starker Trübung ab. Mit $0,01 \%$ iger Lösung zeigen sich erst nach etwa 10 Minuten Störungen in der Bewegung. Nach 20 Minuten haben die meisten ihre Bewegung fast eingestellt, der Infusorienleib beginnt körnig trüb zu werden; nach 30 Minuten sind viele Infusorien schon abgestorben, kugelig, zum Teil geplatzt; nach 24 Stunden sind alle Infusorien tot. Dagegen tötet $0,001 \%$ ige Goldchloridlösung dieselben binnen 24 Stunden nicht.

Nach Knop ist $0,05 \%$ ige Goldlösung giftig für Maispflanzen.

$\mathrm{Zinnchl}$ or ü $\mathrm{r}$ tötet in $1 \%$ iger, ebenso auch in $0,1 \%$ iger Lösung die Infusorien augenblicklich ab unter körniger Trübung.

In $0,01 \%$ iger Zinnchlorürlösung trat bei sehr vielen Infusorien sogleich eine Verlangsamung der Bewegung ein, dann allmählich Stillstand, wobei nur noch hier und da zitternd-zuckende Bewegungen bemerkbar wurden. Nach zweistündigem Liegen war zu meinem Erstaunen wieder alles in lebhaftester Bewegung. Ich setzte nun von neuem $0,01 \%$ ige Zinnchlorürlösung $\mathrm{zu}$; da trat sofort wieder Stillstand der Bewegung ein. Dieselbe stellte sich auch später nach einer Viertelstunde nicht wieder ein; die Infusorien schienen wie $a b$ - 
gestorben; als ich sie aber nach einer Stunde wieder betrachtete, war schon die lebhafteste Bewegung eingetreten.

0,001\% ige Lösung vermochte natürlich gar keine Wirkung zu äussern.

Zinnsalze sind also wohl nicht zu den giftigeren Metallsalzen zu zäblen. B o d l änd e r konnte allerdings an höheren Tieren chronische Veroiftungen durch kleinere Dosen Zinnsalze hervorrufen.

Vielleicht verhält sich's mit dem Zinn äbnlich wie mit dem im periodischen System der Elemente nahestehenden Blei, welches auch für höhere Tiere viel giftiger ist als für niedere.

Essigsaures Blei tötet in 0,1\% iger Lösung die Infusorien $\mathrm{ab}$, aber nicht augenblicklich; einige schwimmen sogar noch ziemlich lange (10 Minuten) umher; es tritt schliesslich eine Trübung des Infusorienleibes ein. Lässt man auf die abgetöteten Infusorien Schwefelwasserstoffwasser einwirken, so tritt eine Bräunlichfärbung ein.

Verdünnt man die Lösung aufs Zehnfache, so ist zunächst keinerlei Einwirkung zu bemerken, wenn man in dieselben frische Infusorien verbringt. Auch nach einer Viertelstunde hat sich noch nichts geändert, nach einer weiteren halben Stunde ebenfalls noch nichts. In dieser $0,01 \%$ igen Bleisalzlösung schienen mir die Infusorien sogar nach 24 stündigem Liegen völlig unverändert zu sein; sie bewegten sich ganz normal, gingen ihrer Nahrung nach -usw. Auch Cladophoren und Vaucherien sterben nicht vollständig $a b$ in dieser Lösung, desgleichen Diatomeen.

Bezüglich der Eisensalze wurde schon (dieses Arch. Bd. 108 S. 221) hervorgehoben, dass $0,1 \%$ ige Lösung von Eisenvitriol die Spirogyren binnen 24 Stunden nur ungefähr zur Hälfte tötet, Lösung von $0,01 \%$ nur ungefähr zum zwanzigsten Teil.

Phanerogamen können in Nährlösungen, welche $0,1 \%$ Eisenvitriol enthalten, über eine Woche am Leben bleiben.

$0,1 \%$ Eisenvitriol verhindert die Fäulnis, $0,02 \%$ aber nicht mehr.

In schwefelsaurem $\mathrm{Nicke} 1$ von $0,1 \%$ sterben Infusorien nicht augenblicklich ab; aber nach 24 Stunden sind alle getötet durch diese Lösung. In $0,01 \%$ iger Lösung sterben sie ebenfalls binnen 24 Stunden. Sogar in $0,001 \%$ iger Lösung fand ich nach 24 stündiger Einwirkung kein lebendes Infusorium mehr. In $0,0001 \%$ iger Lösung aber starb binnen 10 Stunden kein Infusorium ab; anch nach drei Tagen waren die Tiere noch am Leben. 
Nochmals über die Wirkung stark verd. Lösungen auf lebende Zellen. 207

Salpetersaures Kobalt bringt in 0,1\% iger Lösung an Infusorien und kleineren Schwärmern (von Pilznatur) zunächst keine Veränderung hervor. Nach einer Stunde aber sind sie tot. $0,01 \%$ ige Lösung lässt die Infusorien sogar bei 24 stündiger Einwirkung am Leben.

Für höhere Tiere scheinen die Kobaltsalze giftiger $\mathrm{zu}$ sein; denn 2-4 mg Kobaltchlorid töten nach Coppola (T. Th. 15, 76) einen Frosch.

Schwefelsaures Mangan bringt in der Konzentration $0,1 \%$ zunächst gar keine Veränderung an Infusorien hervor; selbst nach 24 stündigem Aufenthalt in der Lösung scheinen die Tiere keinen Schaden genommen zu haben.

Selbst in 1\% iger Manganlösung sterben die Infusorien binnen 5 Minuten nicht $a b$, sie schwimmen hin und her, als ob sie in normalen Verbältnissen wären. Erst nach einer Stunde bemerkte ich, dass die Bewegungen der Infusorien abnorm wurden; sie wichen nicht mehr von der Stelle und führten, sich um ihre Achse drehend, langsam rollende Bewegungen im Kreise aus. Auch andere Mikroorganismen, Bakterien, kleine Schwärmer von Fünftelgrösse der Infusorien lebten noch und bewegten sich. Nach 2 Stunden waren manche Infusorien abgestorben unter starker körniger Trübung, viele bewegten sich, ihren Platz nicht verlassend, nur noch schwach, einige noch sehr lebhaft und beliebig fortschreitend. Sogar nach 24 Stunden waren noch einige lebend und beweglich.

Bezüglich der Einwirkung von Mangansalzen auf höhere (grüne) Pflanzen, wie Gerstenkeimlinge, Rettich, Soyabohne, hat 0 . Loew Versuche publiziert (Allg: bot. Ztg. 1902).

Hiernach üben geringe Mengen Mangan, z. B. 0,02\% Manganosulfat, einen merkwürdigen wachstumfördernden Einfluss aus, was er mit der Beobachtung H. Bertrand's, dass die Oxydasen in Gegenwart von Mangansalzen stärker oxydierende Kraft ausüben, in Zusammenhang bringt (seine eigenen Versucbe bestätigen auch die von Bertrand).

„Worauf beruht nun die wachstumsteigernde Wirkung von Manganoxydulverbindungen? Darauf lässt sich gegenwärtig noch keine ganz bestimmte Antwort geben, wohl aber können wir uns eine Hypothese bilden, welche viel Wahrscheinlichkeit für sich hat. Seit lange ist bekannt, dass Licht das Längenwachstum verlangsamt. Dieses bis jetzt nicht erklärte Phänomen bildet einen sonderbaren 
Gegensatz zu der intensiven chemischen Arbeit, welche das Sonnenlicht in den Chlorophyllkörpern unter Mithilfe des lebenden Protoplasmas dieser Organoide verrichtet. Es wird hier in ausgiebigstem Masse organischer Stoff fabriziert, und doch zugleich die direkte Verwendung desselben als Baustoff rerhindert. Abwesenheit des Lichtes bedingt somit dasselbe Resultat, wie Anwesenheit von Mangan, nämlich Beförderung des Wachstums. Es scheint somit, als ob in beiden Fällen ein Hindernis entfernt würde, welches die Lichtstrahlen hervorrufen, ein Hindernis, welches vielleicht in der Erzeugung von gewissen schädlichen Stoffen in den Zellen unter dem Einflusse des Lichtes besteht. Solche Hemmungsstoffe oder "Ermüdungsstoffe" existieren ja vielfach in den Gewächsen. Es ist nun wahrscheinlich die Rolle der Oxydasen, manche schädliche Nebenprodukte durch partielle Oxydation so zu verändern, dass sie keinen schädlichen Finfluss im grösseren Masse ausüben können ${ }^{1}$ ). Wenn in Abweseuheit des Lichtes nun die Bildung solcher Substanzen sistiert ist, so begreift sich, dass die Oxydasen jetzt ihrer Aufgabe leichter gerecht werden können, und dass die Funktion des Wachstums nicht weiter gehemmt wird.

Nun wird aber, wie wir oben bereits gesehen haben, die W irkung der Oxydasen durch Mangan gesteigert, und es ist deshalb möglich, dass sie nun die partielle oxydation der Hemmungstoffe ebenso rasch ausführen können, als diese gebildetwerden. Da so der hemmende Einfluss des Lichtes aufgehoben ist, kann das Längenwachstum im Lichte ebenso fortschreiten als in der Dunkelheit. Diese Hypothese schliesst natürlich nicht aus, dass andersartige Reizmittel aus einem etwas verschiedenen Grunde ebenfalls wachstumbeschleunigend wirken können."

„Es dürfte vielleicht die Vermutung berechtigt sein, dass das Vorkommen leicht assimilierbarer Manganverbindungen einen nicht zu vernachlässigenden Faktor der natürlichen Fruchtbarkeit gewisser Böden bildet. Leider wird bei Bodenanalysen nur selten der Mangangehalt mitbestimmt, und Vergleiche der Zusammensetzung von Böden mit verschiedenem Grade naturlicher Fruchtbarkeit sind deshalb in dieser Richtung noch nicht möglich."

1) O. L. hat diese Hypothese bereits früher entwickelt im Report No. 59 des U. S. Departement of Agriculture, Washington 1899 p. 27. 
Nochmals über die Wirkung stark verd. Lösungen auf lebende Zellen. 209

Zink und Cadmium üben auf Infusorien nicht augenblicklich einen tödlichen Einfluss aus, wenn man ihre schwefelsauren Salze in $0,1 \%$ iger Lösung einwirken lässt. Bald aber verlangsamen sich die Bewegungen; nach 24 Stunden sind die Infusorien in beiden Lösungen abgestorben, unter körniger Trübung des Infusorienleibes. In 0,01\% iger Lösung der Metallsalze sterben Infusorien binnen 24 Stunden ab. Lässt man sie in $0,001 \%$ iger Zinklösung 24 Stunden liegen, so findet man zwar noch lebende Infusorien vor, aber sie sind von verändertem Aussehen und in ihrer Bewegungsfähigkeit sehr gehemmt. In Cadmiumlösung von $0,001 \%$ waren sie nach 24 Stunden auch schon etwas verändert, aber doch noch von fast ungestörter Beweglichkeit. Nach drei Tagen zeigten sich in der $0,001 \%$ igen Cadmiumsulfatlösung die Infusorien völlig normal; in der $0,001 \%$ igen Zinksulfatlösung aber waren sie alle abgestorben.

Nun versuchte ich noch $0,0001 \%$ ige Zinksulfatlösung, um die Grenze festzustellen. Hier endlich, bei dieser Verdünnung, schienen die Infusorien keinen Schaden zu nehmen; nach 10 Stunden waren sie noch von unveränderter Beweglichkeit, desgleichen nach drei Tagen.

Dass Zinksalze von relativ grosser Schädlichkeit sind, wurde auch sonst beobachtet.

Nob be berichtet, dass Zinksalze für Phanerogamen dreimal so giftig seien als Bleisalze. In Nährlösungen, welche 0,02\% Zinksalz enthalten, sterben die Wurzeln dieser Pflanzen bald ab.

Durch Zinkvitriollösung von $0,01 \%$ wird Cladophora zum Teil getötet (binnen 18 Stunden).

Das Leben der Fäulnispilze wird aber merkwürdigerweise nicht einmal durch $0,1 \%$ Zinksulfat gänzlich gehindert. Denn in einer fäulnisfähigen Lösung, welcher $0,1 \%$ Zinksulfat zugesetzt worden war, trat binnen drei Wochen im Brütofen Fäulnis ein, während $0,1 \%$ Cadmiumsulfat die Fäulnis verhinderte. Hier ist also Cadmium giftiger als Zink. Ähnlich ist es bei Milchsäurebazillen, deren Gärtätigkeit durch $0,015 \%$ Cadmiumsulfat gehemmt wird, während $0,1 \%$ Zinksulfat nicht schädlich wirkt (Richet, Compt. rend. t. 114).

$0,005 \%$ Cadmiumsalz in der Nährlösung wirkt nach Knop giftig auf Maispflanzen; desgleichen $0,005 \%$ Zinksulfat.

Den Uransalzen wird grosse Giftigkeit gegen Tiere nachgesagt. Meine Versuche an Infusorien bestätigen das.

Infusorien sterhen in $0,1 \%$ iger Lösung sofort $a b$, sie trüben 
sich körnig und platzen dann. Auch in $0,01 \%$ iger Lösung stellen die meisten ibre Bewegungen augenblicklich ein (einge junge kleinere Tiere sieht man noch ein paar Minuten langsam umhersehwimmen.) Selbst in $0,001 \%$ iger Uranlösung stellen die Infusorien binnen wenigen Minuten ihre Bewegungen ein. Nach 24 Stunden sah ich nicht bloss in $0,01 \%$, sondern auch in $0,001 \%$ iger Uranazetatlösung sämtliche Infusorien zweifellos abgestorben, unter schwacher Bräunlichfärbung ihres Leibes.

Verdünnt man noch weiter, so dass die Lösung nur $0,0001 \%$ Uransalz enthält, so ist keine Einwirkung mehr zu benerken, auch nicht nach 24 stündigem Verweilen der Infusorien in der Lösung.

Nach 0 . Loew schädigt Uranylnitrat schon bei $0,05 \%$, noch mehr bei $0,2 \%$ junge Erbsen- und Gerstenpflanzen. $0,01 \%$ übt aber keinen schädlichen Einfuss auf dieselben. 0,0002\% wirkt (bei sechsmaliger Erneuerung der Lösung) stimulierend. (Agric. Tokio Imperial Univ. vol. 5 No. 2.)

In $0,1 \%$ iger Überosmiumsäure sterben die Infusorien augenblicklich ab. Sogar in 0,01\% iger Lösung stehen die meisten binnen wenigen Minuten still; allein nach einer halben Stunde schwinmen sehr viele derselben wieder lebhaft hin und her; nach 24 Stunden scheinen sie alle wieder lebhaft beweglich geworden zu sein.

Da die Überosmiumsäure als spezifisches Reagens auf Fett bekannt ist, dürfte die relativ geringe Giftigkeit derselben wohl darauf zurückzufüren sein, dass dieselbe von den Fettstoffen in Beschlag genommen wird.

Anderweitige Angaben über die Einwirkung der Überosmiumsäure auf Tiere und Pflanzen konnte ich in der Literatur nicht finden.

Wenn wir die Wirkung der Schwermetallsal ze überblicken, so fällt zunächst auf, dass kein einziges ganz unschädliches darunter ist, und dass manchen eine enorme Reaktionsfähigkeit gegen lebendes Plasma zukommt ( $\mathrm{Hg}, \mathrm{Ag}, \mathrm{Cu}$.$) .$

Von medizinischer Seite wurde diesen Stoffen schon lange Beachtung geschenkt. Wegen ihrer grossen Verwandtschaft zu den Eiweisskörpern rufen sie nur örtliche, keine allgemeine Vergiftung bervor, da sie in den ersten Nahrungswegen an die Eiweisskörper der Schleimhäute festgebunden und mit dem zerstörten Gewebe wieder ausgeschieden werden; sie gelangen nicht ins Blut. Werden sie aber oft gegeben oder als Doppelsalze, Albuminate und dergl. 
Nochmals uber die Wirkung stark verd. Lösungen auf lebende Zellen. 211

eingeführt, dann gelangen sie ins Blut und werden auch dort nicht niedergeschlagen; nun sind sie imstande, eine akute allgemeine Vergiftung herbeizuführen (Nothnagel und Rossbach, Arzneimittellehre S. 114).

Von den freien Halogenen ist schon seit einiger Zeit bekannt, dass sie noch bei grossen Verdünnungen Giftwirkung äussern; ebenso von dem Wasserstoffsuperoxyd, ferner den übermangansauren Salzen. Sie gehören nach O. Loew zu den Giften, welche durch Oxydation auf das Plasma wirken.

„Die Halogene wirken bei so labilen Substanzen, wie sie das lebende Protoplasma bilden, in erster Linie oxydierend, indem sie Wasser spalten, Halogenwasserstoff bilden und den Sauerstoff auf die organische Substanz werfen; so verhält sich ja auch z. B. Brom gegen Glukose. Nach Binz bilden die Halogene, wenn sie in das alkalische Blut gelangen, auch Sauerstoffsalze (Hypochlorit, Jodat), indes dürfte das gebildete Hypochlorit wohl nur sehr kurze Zeit im Blut existenzfähig bleiben, da es ausserordentlich oxydierend wirkt. An eine substituierende Wirkung der Halogene kann wobl beim Protoplasma erst gedacht werden, wenn es tot ist" ( 0 . Loew a. a. O. S. 15).

Nach meinen Beobachtungen wurden Algen und Infusorien durch Chlorlösung von 1:10000 binnen einer Stunde getötet unter Bleichung und Kontraktion des Inhaltes. Als ich die Verdünuung noch weiter steigerte, zeigte sich, dass durch Lösung 1:20000 binnen 24 Stunden ebenfalls alle Organismen abstarben, desgleichen durch Lösung 1:50000; sogar durch 1:100000 wurde der Tod herbeigeführt, nur wenige Zellen waren in letzterem Falle ausgenommen; die toten Algenfäden waren gebleicht.

B rom im freien Zustand wirkt ebenfalls sehr giftig auf Spirogyra, Cladophora, Diatomeen, Oscillarien, Infusorien usw. Binnen wenigen Stunden stellt sich in Lösung 1:10000 Erschlaffung der Fäden und Verfärbung des Chlorophylles ein; der Tod ist allenthalben eingetreten. Lösung 1:20000 tötet binnen 24 Stunden nicht unbedingt alle Tiere und Pflanzenzellen, man findet nach dieser Zeit noch einige lebende Infusorien, Diatomeen, Würmer, Algenzellen darin vor. Lösung 1 : 50000 liess die gesamten Algen und niederen Tiere unverändert, desgleichen natürlich auch Lösung $1: 100000$.

Freies Jod wirkte ebenfalls noch bei einer Verdünnung von 1 : 10000 tödlich auf Algen und Infusorien ein. In den Algenfäden 
kontrahierte sich der Plasmaschlauch, und die Stärkekörner nahmen eine blaue Farbe an. Durch Lösung 1:20000 wurden binnen 24 Stunden sämtliche eingesetzten Algen und niederen Tiere getötet, desgleichen durch Lösung 1:50000. In Lösung 1:100000 fanden sich zu dieser Zeit noch lebende Algen vor; von Clarlophora waren die dünneren Zweige abgestorben, die dicken Äste noch am Leben.

Für Hefe sind die freien Halogene ebenfalls starke Gifte. Chlor wirkt auf sie noch bei einer Verdünnung 1:10000 tödlich, Jod ebenfalls; durch Brom in der Veriünnung $1: 10000$ wird das Wachstum und auch die Gärtätigkeit der Hefe nicht unterdrückt. Chlor von 1:50000 lässt ebenfalls die Gärung einer zuckerhaltigen Flüssigkeit aufkommen.

Lässt man freies Chlor auf Fäulnisbakterien einwirken, so findet man, dass jenes bei einer Verdünnung von 1: 100000 nicht mehr sehädlich wirkt; die Fäulnis einer Peptonlösung tritt unter diesen Verhältnissen schon binnen 2 Tagen ein.

Wasserst offsuperoxyd liefert "aktivierten" atomistischen Sauerstoff bei seiner Spaltung im Plasma und ist deswegen giftig.

Ein cem käufliches Wasserstoffsuperoxyd (ca. 10\%) auf ein Liter Wasser tötet nach 24. Stunden die gewöhnlichen Wassermikroben, wie Althö fer (Ch. C. 1890) feststellte; das bedeutet, dass ungefähr $0,01 \% \quad \mathrm{H}_{2} \mathrm{O}_{2}$ letztere vergiften kann.

Paneth fand, dass $1 / 10000 \mathrm{H}_{2} \mathrm{O}_{2}$ sämtliche zilierten Infusorien eines Heuaufgusses binnen 15-30 Minuten tötete. Selbst bei $1: 20000$ überlebte nur ein Teil der Tiere. Algen, welche in $0,1 \%$ völlig. neutraler $\mathrm{H}_{2} \mathrm{O}_{2}$-Lösung 10-12 Stunden verweilen, sterben ab. Eine $10 \%$ ige neutralisierte Lösung wirkt augenblicklich tödlich auf Infusorien. Wurzeln von Vicia und Trianea dagegen können einige Zeit in $0,1 \%$ iger Wasserstoffsuperoxydlösung ohne Schaden verweilen, ebenso Staubfäden von Tradescantia (Pfeffer). Frösche zeigen narkotische Erscheinungen, wenn sie in $1 \%$ ige Lösung gesetzt werden (Bodländer), und $25 \mathrm{ccm}$ einer $4 \%$ igen $\mathrm{H}_{2} \mathrm{O}_{2}$-Lösung reichen hin, einen $3 \mathrm{~kg}$ schweren Hund zu töten unter Symptomen ähnlich denen, welche Bert bei Anwendung komprimierten Sauerstoffes beobachtete. Bei intravenöser Infektion wird der Tod durch Stillstand der Respiration bedingt (Laborede).

Dass $\mathrm{Kaliumpermanganat}\left(\mathrm{KMnO}_{4}\right)$ giftig auf Infusorien einwirkt, hat $\mathrm{Binz}$ festgestellt; er fand, dass $0,2 \%$ dieselben binnen einer Minute tötet. 
Nach meinen Untersuchungen sind noch weit grössere Verdünnungen giftig, wenigstens für Algen; denn in Lösung 1 : 50000 blieben die Algen zwar sechs Stunden lang grün, aber die Zellen starben zum Teil ab, indem die Chlorophyllkörner in Unordnung gerieten und der Plasmaschlauch sich kontrahierte; lebende Infusorien und Würmer, Insektenlarven usw. waren bier noch aufzufinden; desgleichen bei Lösung 1:100000. Nach weiteren 18 Stunden waren in letzterer Lösung auch noch sämtliche Infusorien, Diatomeen, Würmer, Insektenlarven usw. am Leben, desgleichen die Cladophoren und sonstigen Fadenalgen. Bei Verdünnung 1:100000 scheint also hier die Giftwirkung aufzuhören. In Lösung 1:50000 stellte sich nach sechs Stunden schon die Giftwirkung etwas ein.

In Lösung 1:20000 starben binnen sechs Stunden alle Algen und Infusorien unter Braunfärbung des Plasma's ab; die Algenfäden wurden schlaff und hatten schmutzig-rotbraune Farbe angenommen.

Kaliumpermanganat wirkt nach O. Loew (Giftwirkungen S. 16) „aktiv oxydierend" auf das Zellplasma ein und tötet dasselbe hierdurch. Die Oxydationskraft dieses Stoffes ist ja überhaupt sehr gross, er wirkt schon bei gewöhnlicher Temperatur auf viele organische Stoffe.

Für Fäulnisbakterien ist Kaliumpermanganat ebenfalls ein hochgradiges Gift. Zwar konnte ich Versuche derselben Art wie die bisher beschriebenen mit dieser Substanz nicht so anstellen, dass sie direkt vergleichbar waren; denn das zugesetzte Gift wird hier zum Teile von den (ausser den Bakterien) vorhandenen organischen Substanzen, wie Pepton, in Beschlag genommen. Trotzdem konnte ich feststellen, dass in einer fäulnisfähigen Lösung, welche mit $0,002 \%$ Kaliumpermanganat versetzt war, binnen drei Tagen keine Fäulnis eintrat, während in einer garz gleichen zweiten Flüssigkeit obne Perınanganat stinkende Fäulnis sich zeigte. Ja sogar durch Zusatz von nur 0,001\% Kaliumpermanganat wurde die Fäulnis etwas hintangehalten.

Das übermangansaure Kali darf also zu den stärksten Antiseptika gerechnet werden.

$\mathrm{Kalium} \mathrm{ehl} \mathrm{or} \mathrm{at}\left(\mathrm{KClO}_{3}\right)$ ist bemerkenswerterweise viel weniger schädlich als die bisher betrachteten Oxydationsgifte.

Spaltpilzvegetationen werden erst durch $2 \%$ ige Lösungen geschädigt; sind die Lösungen verdünnter, so findet eine Reduktion zu $\mathrm{KCl}$ durch die fortlebenden Pilze statt (Binz), wenn gute Nährstoffe 
vorhanden sind. Aeroben vertragen bis zu $3 \%$. Nach Manassein werden Schimmelvegetationen sogar durch $7 \% \mathrm{KClO}_{3}$ in der Nährlösung nicht geschädigt.

O. Loew beobachtete, dass Buchweizenkeimlinge in Nährlösungen mit $0,01 \% \mathrm{KClO}_{3}$ nach drei Wochen unter Erbleichen der Blätter abstarben. Spirogyren starben in $0,01 \%$ Lösung des Salzes nach einer Reihe von Tagen. Algen und böhere grüne Pflanzen scheinen demnach wesentlich empfindlicher zu sein. Vermutlich vermögen die Chlorophyllapparate eine Abspaltung des Sauerstoffes leichter zu bewirken als die nicht grünen Plasmaapparate.

Es gehört bei chlorsaurem Kali (nach O. L oew, a. a. O. S. 17) überhaupt ein äusserer Anstoss dazu, um die oxydierende Wirkung auszulösen; "dieser Anstoss wird durch die energischen Schwingungen im lebenden Plasma gegeben". Zucker (Gluhose) wird direkt von $\mathrm{KClO}_{3}$ nicht oxydiert. Wenn man aber Platinmohr dazu setzt, so beginnt sofort eine Übertragung von Sauerstoff auf den Zucker, es wird Chlorkalium gebildet, was mit Silbernitrat bald nachgewiesen werden kann.

Schlussbemerkungen. Die Verdünnungen, in welchen viele Substanzen noch auf das lebende Protoplasma reagieren, d. h. sich mit dem aktiven Eiweiss desselben chemisch verbinden, sind staunenswert, in einzelnen Fällen geradezu beispiellos. Eine unten folgende tabellarische Zusammenstellung wird hierüber einigen Überblick gewähren.

Einstweilen seien einige als empfindlich bekannte chemische Reaktionen zum Vergleiche angeführt.

Lässt man Säuren und Basen auf Lackmuspapier einwirken, so erfolgt bekanntlich mit ersteren eine Rot,- mit letzteren eine Blaufärbung. Besonders empfindliche Lackmuspapiere können von Chemikalienhandlungen, Apotheken usw. bezogen werden.

Mit $0,01 \%$ Schwefelsäure gibt empfindliches Lackmuspapier sogleich eine deutliche Rotfärbung. Sogar in $0,001 \%$ färbt es sich noch ein wenig. Mit $0,0002 \%$ aber tritt keine Veränderung ein.

Macht man denselben Versuch mit Natriumhydroxyd, so tritt schon bei $0,01 \%$ die Reaktion nur schwach und allmählich ein. Am besten ist es, man taucht den Lakmusstreifen stark ein und hängt ihn dann auf, so dass die nicht ganz in den Poren festgehaltene Flüssigkeit in einem grossen Tropfen an der unteren Kante sich sammelt. Hier bemerkt man dann deutliche Blaufärbung, jedenfalls 
Nochmals über die Wirkung stark verd. Lösungen auf lebende Zellen. 215

infolge von allmählicher Aufsammlung der Base. Schon in Lösung $0,002 \%$ tritt aber keine Spur von Reaktion mehr ein.

Eine andere als empfindlich bekannte Reaktion ist die zwischen Jod und unterschwefligsaurem Natron; letzteres wird als „Fixiernatron" in der Photographie angewendet und muss, da es ein gefürchtetes bildverderbendes Mittel ist, sorgfältigst ausgewaschen werden. Zur Probe, ob es völlig entfernt sei, wendet man blaue Jodstärke an: $1 \mathrm{~g} \mathrm{Jod} \mathrm{in} 25 \mathrm{ccm}$ Alkohol, ferner $1 \mathrm{~g}$ Stärke auf $100 \mathrm{~g}$ kochendes Wasser; beide werden gemischt, von der Lösung gibt man einige Tropfen in ein Reagenzglas, dann giesst man das zu prüfende Waschwasser darauf. Es tritt sogar bei 1 Millionstel Verdünnung des unterschwefligsauren Natron noch Entfärbung ein, indem Jod in Jodnatrium verwandelt wiri; das ist aber die äusserste Verdünnung, bei welcher die Reaktion noch gelingt.

$$
2 \mathrm{~S}_{2} \mathrm{O}_{3} \mathrm{Na}_{2}+2 \mathrm{~J}=\mathrm{S}_{4} \mathrm{O}_{6} \mathrm{Na}_{2}+2 \mathrm{NaJ} \text {. }
$$

Es gibt dann noch eine weitere Probe, welche mit einer (mit Essigsäure) angesäuerten $2 \%$ igen Silbernitratlösung ausgeführt wird. 1-2 ccm dieser Lösung werden in ein Becherolas gegeben, in welchem sich das zu prüfende Waschwasser befindet. Etwa anwesendes Fixiernatron ruft

bei $0,1 \%$ Verdünnung binnen 10-30 Sekunden Braunfärbung,

$$
\begin{aligned}
& \text { "0,01\% " " " " deutliche Gelb- } \\
& \text { " } 0,001 \% \quad \text { \% } \quad \text { " } \quad \text { neine Färbung }
\end{aligned}
$$

hervor.

Letztere Reaktion ist also nicht so empfindlich wie erstere, aber immer noch recht instruktiv für den Einfluss der Verdünnung auf das Gelingen der chemischen Reaktionen.

Über das Verhalten von Silberlösungen gegen verschiedene organische Stoffe hat $O$. Loew Untersuchungen gemacht (Chem. Kraftquelle im leb. Protopl. S. 10 ff.); ebenso über einige andere Schwermetallsalze.

Neutrale Silberlösung ist hiernach nur von wenigen organischen Körpern reduzierbar; mehrfach hydroxylierte Benzolderivate gehören $\mathrm{zu}$ diesen wenigen. Alkalische Silberlösung aber wird von vielen reduziert, hydroxylierte Benzolderivate sind hiergegen sehr empfindlich.

Ketone wirken nur auf relativ konzentrierte Lösungen ein.

Salze von Hydroxysäuren; wie Weinsäure, wirken auf $1 \%_{0}^{\circ}$ ige alkalische Silberlösung kaum mehr ein. 
Aldehyde reagieren gegen alkalische Silberlösung noch bei Verdünnung $1: 200000$.

I)ass das lebende Protoplasmaeiweiss aus alkalischer Silberlösung noch bei Verdünnung 1:100000 oder sogar 1:1 Million Silber abscheidet (infolge seiner Amido-Aldehydbeschaffenheit), wurde von o. Loew und Verfasser früher hervorgehoben.

Pyrogallol, Gallussäure und Gerbsäure vermögen bereits das Silber nicht mehr aus alkalischer Lösung abzuscheiden, wenn diese weniger als 1/12000 $\mathrm{AgNO}_{3}$ enthält. Ameisensaure Salze reagieren schon bei dem 12 fachen dieses Silbergehaltes nicht mehr.

Äthylaldehyd wird durch alkalische Goldlösung noch bei Verdünnung $1: 200000$ oxydiert unter Abscheidung des Goldes aus der Lösung.

Alkalische Osmium- und Palladiumlösung dagegen geben selbst bei $1 \%$ Metallgehalt mit Äthylaldehyd bei gewöhnlicher Temperatur nur sehr allmählich eine Metallabscheidung, und bei der zehnfachen Verdünnung erfolgt dieselbe selbst beim Erwärmen äusserst langsam. Die äusserst sehwache, nur unter Mitwirkung von Wärme zu erreichende Endreaktion liegt etwa bei einem Verhältnis von 1 Teil Metall auf 12000 Teilen Wasser. Ähnlich sind die Verhältnisse beim Platin.

Alkalische Quecksilberlösung wird durch Aldehyde höchstens noch bei $1: 2000$ reduziert, durch Glykose und Gerbstoff aber noch bis $1: 6000$.

Bekannte Reaktionen sind die zwischen Gerbstoff und Eisenoxydsalzen, ferner zwischen Schwefelcyankalium (Rhodankalium) und Eisenoxydsalzen; endlich zwischen gelbem Blutlaugensalz und Eisenoxydsalzen.

Gerbstoff (oner Gallustinktur) gibt bekunntlich mit Eisenoxydsalzen einen blauen bis schwarzen Niederschlag.

Schwefelcyankalium (Rhodankalium) erzeugt eine blutrote, nicht durch Salzsäure, aber durch essigsaures Natron verschwindende Färbung.

Gelbes Blutlaugensalz (Ferrocyankalium) erzeugt in Salzsäure unlösliches Eisencyanürcyanid (Berlinerblau):

$$
3\left[\mathrm{FeCy}_{2}+4 \mathrm{KCy}\right]+2 \mathrm{Fe}_{2} \mathrm{Cl}_{6}=\underbrace{3 \mathrm{FeCy}_{2}, 2 \mathrm{Fe}_{2} \mathrm{Cy}_{6}}_{\text {Berlinerblau }}+12 \mathrm{KCl} \text {. }
$$


Nochmals über die Wirkung stark verd. Lösungen auf lebende Zellen. 217

Weṇ man eine $0,01 \%$ ige, mit etwas freier Salzsäure versetzte Eisenchloridlösung mit der Lösung des gelben Blutlaugensalzes versetzt, so erfolgt augenblicklich eine starke Blaufärbung der Flüssigkeit.

In 0,001\% \% iger Lösung tritt auch sogleich eine grün-blaue Färbung ein.

Sogar $0,0001 \%$ ige Eisenchloridlösung zeigt bei Zusatz von Ferrocyankalium noch eine schwache grünliche Färbung.

Hier aber dürfte die Grenze der Reaktionsfähigkeit nahezu liegen.

In einer $0,01 \%$ igen, mit freier Salzsäure versetzten Eisenchloridlösung bringt Gerbsäure (Tannin) sogleich eine tintenartige, blauschwarze Färbung hervor.

In $0,001 \%$ iger Lösung vermag Gerbsäure kaum noch eine Spur von Dunkelfärbung hervorzubringen.

0,0001\% ige Eisenchloridlösung wird von Gerbsäure absolut nicht verändert.

Die Grenze der Reaktion liegt also schon bei $0,001 \%$.

$0,01 \%$ ige, mit Salzsäure angesäuerte Eisenchloridlösung wird von Rhodankaliumlösung sogleich blutrot gefärbt.

In 0,001\%iger Lösung ruft Rhodankalium augenblicklich eine gelbrote Färbung hervor.

0,0001\% ige Eisenchloridlösung wird von Rhodankalium gerade noch etwas gelblich gefärbt, so dass man an dickeren Schichten der Lösung einen gelben Schein wahrnimmt.

Die Grenze der Reaktionsfähigkeit ist also hier mit $0,0001 \%$ erreicht.

Wenn wir die angegebenen Versuche über chemische Reaktinnsfähigkeit überblicken, so sehen wir, dass manche Reaktionen schon bei Verdünnung 1:100 aufhören, einzutreten, andere bei $1: 1000$, wieder andere bei 1:10000; selten sind Reaktionen, die bei Verdünnung 1:1 Million noch gelingen.

Nun möge zum Vergleich eine tabellarische Zusammenstellung von physiologischen Reaktionen, d. h. Reaktionen zwischen Protoplasmaeiweiss und verschiedenen Substanzen, Platz finden. 
Tabellarische Übersìcht der Verdünnungsgrade verschìedener Gifte und ihrer Wirkung.

\begin{tabular}{|c|c|c|}
\hline $\begin{array}{c}\text { Bezeichnung } \\
\text { der schädlichen } \\
\text { (verbindungs fähigen) } \\
\text { Substanz }\end{array}$ & $\begin{array}{c}\text { Verhalten bei grossen } \\
\text { Verdünnungen }\end{array}$ & $\begin{array}{c}\text { Sonstige } \\
\text { Bemerkungen }\end{array}$ \\
\hline Schwefelsäure & $\begin{array}{l}0,1 \text { oder } 1 \% \text { tötet Paramäcien augen } \\
\text { blicklich. Fadenalgen reagieren } \\
\text { nicht sogleich auf } 0,1 \% \text {. } 0,01 \% \\
\text { tötet weder Algen noch niedere } \\
\text { Tiere, auch nicht, wenn sie in } \\
\text { grossem Ubberschuss angewendet } \\
\text { wird; sie scheint vielmehr als } \\
\text { Anreiz zu lebhafterer Tätigkeit } \\
\text { zu wirken. }\end{array}$ & $\begin{array}{l}\text { Schwefelsäure verbindet } \\
\text { sich also wohl bei } \\
0,1 \% \text { nicht aber bei } \\
0,01 \% \text { mit Plasma- } \\
\text { eiweiss. }\end{array}$ \\
\hline Salzsäure & $\begin{array}{l}\text { In } 0,01 \% \text { hören binnen wenigen } \\
\text { Minuten alle Bewegungen auf; } \\
\text { sogar 0,001\% wirkt tödlich auf } \\
\text { Paramäcien und Schwärmsporen. }\end{array}$ & $\begin{array}{l}\text { Salzsäure verbindet sich } \\
\text { leichter als Schwefel- } \\
\text { säure. Manche Zellen } \\
\text { sind freilicb wider- }\end{array}$ \\
\hline Weinsäure & $\begin{array}{l}\text { In } 0,1 \% \text { sterben Infusorien sogleich, } \\
\text { Algen binnen } 24 \text { Stunden ab. } \\
\text { Anguillula-Arten und Diatomeen } \\
\text { bleiben aber beweglich. - } 0,01 \% \\
\text { scheint den meisten Mikro. } \\
\text { organismen nicht zu schaden. }\end{array}$ & 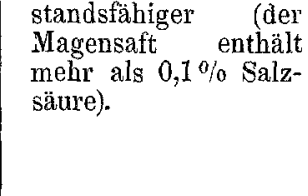 \\
\hline Kalziumhydroxyd & $\begin{array}{l}0,1 \% \text { ige Lösung tötet Infusorien } \\
\text { augenblicklich; auchandereMikro- } \\
\text { organismen leiden bald Schaden, } \\
\text { nach } 24 \text { Stunden ist alles tot. - } \\
\text { Nach o. Loe w tötet sogar } \\
0,015 \% \text { ige Lösung die Faden- } \\
\text { alge Spirogyra. Bei meinen Ver- } \\
\text { suchen zeigten sich Infusorien } \\
\text { widerstandstähig gegen } 0,01 \% \text {, } \\
\text { von den vorhandenen Fadenalgen } \\
\text { starb nur ein Teil ab. }\end{array}$ & $\begin{array}{l}\text { Nur bei e inem Orga- } \\
\text { nismus, dem Typhus- } \\
\text { bazillus, ist eine über } \\
\text { nebenstehende An- } \\
\text { gaben binausgehende } \\
\text { Empfindlichleit be- } \\
\text { obachtet worden } \\
(0,007 \% \text { Ätzkalk noch } \\
\text { tödlich). }\end{array}$ \\
\hline Kaliumhydroxyd & $\begin{array}{l}\text { In } 0,1 \% \text { iger Lauge sterben Para- } \\
\text { mäcien augenblicklich ab; durch } \\
0,01 \% \text { werden sie auch bei } \\
\text { längerem Aufenthalt nicht getötet. } \\
0,05 \% \text { macht die Plasmaströmung } \\
\text { der Characeen auf hören. }\end{array}$ & \\
\hline Dinatriumphosphat & $\begin{array}{l}\text { ist so viel wie unschädlich, trotz } \\
\text { seiner ziemlich kräftigen alka- } \\
\text { lischen Reaktion; erst wenn die } \\
\text { Konzentration bis zu } 2,5 \% \text { steigt, } \\
\text { wirkt es schädlich durch Wasser- } \\
\text { entzug (wie ganz neutrale Salze, } \\
\text { z. B. Kochsalz, auch). }\end{array}$ & \\
\hline $\begin{array}{l}\text { Salpetersaures } \\
\text { Quecksilberoxyd }\end{array}$ & $\begin{array}{l}\text { Sogar } 0,001 \% \text { schädigt Infusorien } \\
\text { fast augenblicklich; binnen } \\
\text { wenigen Minuten tritt der Tod } \\
\text { ein unter Trübung. } 0,01 \% \text { wirkt } \\
\text { wie auch } 0,1 \% \text { momentan tödlich. }\end{array}$ & $\begin{array}{l}\text { DieabgestorbenenInfus. } \\
\text { sind körnig getrübt. } \\
\mathrm{H}_{2} \mathrm{~S} \text { ruft Dunkel- } \\
\text { färbung hervor. }\end{array}$ \\
\hline
\end{tabular}


Nochmals über die Wirkung stark verd. Lösungen auf lebende Zellen. 219

\begin{tabular}{|c|c|c|}
\hline $\begin{array}{c}\text { Bezeichnung } \\
\text { der' schädlichen } \\
\text { (verbindungsfähigen) } \\
\text { Substanz }\end{array}$ & $\begin{array}{c}\text { Verhalten bei grossen } \\
\text { Verdünnungen }\end{array}$ & $\begin{array}{c}\text { Sonstige } \\
\text { Bemerkungen }\end{array}$ \\
\hline $\begin{array}{l}\text { Quecksilberchlorid } \\
\text { (Sublimat) }\end{array}$ & $\begin{array}{l}\text { schädigt Algenzellen noch bei Ver- } \\
\text { dünnung } 1: 100 \text { Millionen, sogar } \\
1: 1000 \text { Millionen, wenn man die } \\
\text { Lösung in genügender Menge } \\
\text { lange genug einwirken lässt. }\end{array}$ & $\begin{array}{l}\text { 0,0003\% } \% \text { hindert dieAus- } \\
\text { keimung der Milz- } \\
\text { brandsporen(R.Koch). } \\
\mathrm{H}_{2} \mathrm{~S} \text { ruft an getöteten } \\
\text { AlgenSchwarzfärbung } \\
\text { in Zellkern u. Plasma } \\
\text { bervor. }\end{array}$ \\
\hline $\begin{array}{l}\text { Salpetersaures Silber } \\
\text { (Höllenstein) }\end{array}$ & $\begin{array}{l}0,001 \% \text { tötet Infusorien. } \quad 0,0002 \% \\
\text { hindert die Fäulnis. }\end{array}$ & $\begin{array}{l}\text { MitSchwefelwasserstoff- } \\
\text { wasser nehmen die } \\
\text { getöteten Infusorien } \\
\text { eine starke Bräunlich- } \\
\text { färbung an. }\end{array}$ \\
\hline $\begin{array}{l}\text { Kupfervitriol }\left(\mathrm{CuSO}_{4}\right. \\
\left.\quad+5 \mathrm{H}_{2} \mathrm{O}\right)\end{array}$ & $\begin{array}{l}\text { In } 0,1 \% \text { sterben Infusorien augen- } \\
\text { blicklich unter Trübung ab; in } \\
0,01 \% \text { leben nur die widerstands- } \\
\text { fähigeren einige Minnten weiter, } \\
\text { dann stellen auch sie die Be- } \\
\text { wegung ein. Fäulnisbakterien } \\
\text { entwickeln sich nicht bei Gegen- } \\
\text { wart von } 0,001 \% \% \text { Vitriol, wohl } \\
\text { aber bei } 0,0002 \% .- \text { Fadenalgen } \\
\text { (Cladophora, Conferva, Vaucheria, } \\
\text { Spirogyra etc.) sterben binnen } \\
2 \text { Tagen in Lösung } 0,002 \% \text { ab. } \\
\text { - Spirogyren werden durch } \\
\text { 0,000001 \% o schon binnen } 24 \text { Stun- } \\
\text { den geschädigt, besonders in den } \\
\text { Chlorophyllapparaten. }\end{array}$ & $\begin{array}{l}\text { Mit } \mathrm{H}_{2} \mathrm{~S} \text { nehmen die } \\
\text { getöteten Infusorien } \\
\text { dunklereFarbean. Ge- } \\
\text { töteteAlgenschwärzen } \\
\text { sich mit Schwefel- } \\
\text { wasserstoffwasser in } \\
\text { Zellkern und Plasma. } \\
\text { Manche Schimmel- } \\
\text { pilze wachsen noch } \\
\text { bei Gegenwart von } \\
1 \% \text { Kupfervitriol! }\end{array}$ \\
\hline Goldchlorid & $\begin{array}{l}0,1 \% \text { tötet Infusorien augenblick- } \\
\text { lich, } 0,01 \text { erst binnen } 30 \text { Minuten } \\
\text { (manche widerstandsfähigeren } \\
\text { Indiv. erst binnen } 24 \text { St.), } 0,001 \% \\
\text { tötet sie binnen } 24 \text { Stunden nicht. } \\
\frac{0,05 \% \text { ige Goldlösung ist giftig }}{\text { für Maispflanzen ( } \mathrm{K} n \mathrm{o} \text { ) }} \text {. }\end{array}$ & $\begin{array}{l}\text { Abgetötete Infirsorien } \\
\text { körnig getrübt. }\end{array}$ \\
\hline Zinnchlorür & $\begin{array}{l}0,1 \% \text { tötet Infusorien momentan; } \\
0,01 \% \text { betäubt sie, dann nehmen } \\
\text { sie ihre ursprüngliche Bewegung } \\
\text { wieder an. }\end{array}$ & \\
\hline $\begin{array}{l}\text { Essigsaures Blei } \\
\text { (Bleizucker) }\end{array}$ & $\begin{array}{l}0,1 \% \text { tötet die resistenteren In- } \\
\text { fusorien erst binnen } 10 \text { Minuten. } \\
\text { In } 0,01 \% \text { bleiben sie } 24 \text { Stunden } \\
\text { lang völlig unverändert; auch } \\
\text { Diatomeen und die Fadenalgen }\end{array}$ & $\begin{array}{l}\text { Abgetötete Infusorien } \\
\text { körniggetrübt. Schwe- } \\
\text { felwasserstoff ruft } \\
\text { Braunfärbung hervor. }\end{array}$ \\
\hline
\end{tabular}




\begin{tabular}{|c|c|c|}
\hline $\begin{array}{c}\text { Bezeichnung } \\
\text { der schädlichen } \\
\text { (verbindungsfähigen) } \\
\text { Substanz }\end{array}$ & $\begin{array}{l}\text { Verhalten bei grossen } \\
\text { Verdünnungen }\end{array}$ & $\begin{array}{c}\text { Sonstige } \\
\text { Bemerkungen }\end{array}$ \\
\hline $\begin{array}{l}\text { Schwefelsaures Kads } \\
\text { mium }\end{array}$ & $\begin{array}{l}0,001 \% \text { ist unschädlich für In- } \\
\text { tusorien; } 0,01 \% \text { tötet erst binnen } \\
24 \text { Stunden. } 0,1 \% \text { tötet erst } \\
\text { nach Stunden, die Bewegungen } \\
\text { verlangsamen sich allmählich. }\end{array}$ & \\
\hline $\begin{array}{l}\text { Schwefelsaures Zink } \\
\text { (Zinkvitriol) }\end{array}$ & $\begin{array}{l}\text { Erst bei } 0,0001 \% \text { nehmen die In- } \\
\text { fusorien keinen Schaden; } 0,001 \% \\
\text { tötet binnen } 3 \text { Tagen; } 0,01 \% \\
\text { binuen } 24 \text { Stunden; } 0,1 \% \text { nicht } \\
\text { augenblicklich. }\end{array}$ & $\begin{array}{l}\text { Abgetötete Infusorien } \\
\text { körnig getrübt. }\end{array}$ \\
\hline Eisenvitriol & $\begin{array}{l}0,1 \% \text { tötet Spirogyren binnen } \\
24 \text { Stunden nur ungefähr zur } \\
\text { Hälfte; Blutenpflanzen bleiben } \\
\text { eine Woche lang am Leben. } \\
0,1 \% \text { hindert die Fäulnis, } 0,02 \% \\
\text { nicht. }\end{array}$ & \\
\hline Schwefels. Nickel & $\begin{array}{l}\text { In } 0,1 \% \text { sterben Infusorien nicht } \\
\text { augenblichlich, aber nach } 24 \text { Std.; } \\
0,01 \% \text { tötet sie binnen } 24 \text { Std.; } \\
\text { ebenso } 0,001 \% \text {. } 0,0001 \% \text { schadet } \\
\text { binnen } 3 \text { Tagen nicht. }\end{array}$ & \\
\hline Salpetersaur. Kobalt & $\begin{array}{l}0,1 \% \text { tötet nicht augenblicklich, } \\
\text { aber binnen } 1 \text { Stunde; 0,01\% } \\
\text { schadet binnen } 24 \text { Stunden nicht. }\end{array}$ & \\
\hline Schwefels. Mangan & $\begin{array}{l}0,1 \% \text { tötet binnen } 24 \text { Stunden nicht. } \\
1 \% \text { tötet erst binnen } 1 \text { Stunde } \\
\text { manche weniger resistente In- } \\
\text { fusorien. }\end{array}$ & \\
\hline Uranazetat & $\begin{array}{l}0,1 \% \text { tötet Infusorien sofort. In } \\
0,01 \% \text { und auch in } 0,001 \% \\
\text { stellen Infusorien augenblicklich } \\
\text { oder in wenigen Minuten ihre } \\
\text { Bewegung ein, nach } 24 \text { Stunden } \\
\text { sind sie abgestorben. } 0,0001 \% \\
\text { ist nicht schädlich. }\end{array}$ & $\begin{array}{l}\text { Körnige Trübung der } \\
\text { abgestorbenen Zellen. } \\
\text { Nach } 0 \text {. L o ew schä- } \\
\text { digt } 0,05 \% \text { Uranyl- } \\
\text { nitrat junge Erbsen- } \\
\text { und Gerstenpflanzen, } \\
0,01 \% \text { ist nicht mehr }\end{array}$ \\
\hline Überosmiumsäure & $\begin{array}{l}0,1 \% \text { tötet Infusorien momentan; } \\
0,01 \% \text { lähmt die Bewegung zuerst, }\end{array}$ & $\begin{array}{l}\text { schädlich; } 0,0002 \% \\
\text { wirkt stimulierend. }\end{array}$ \\
\hline
\end{tabular}

Halogene (freie) nach 24 Stunden schwimmen sie wieder lebhaft hin und her.

$0,01 \%$ Chlor tötet binnen 1 Stunde Algen und Infusorien, $0,005 \%$ binnen 24 Stunden, desgleichen $0,002 \%$ und $0,001 \%$. - Brom ist etwas weniger energisch, tötet schon bei $0,005 \%$ binnen 24 Std. nicht alle Algen und Infusorien; 0,002 und $0,001 \%$ sind unschädlich. - Jod ist noch bei $0,002 \%$ tödlich für Algen und Infusorien binnen 24 Stunden; bei $0,001 \%$ finden sich nach 24 Stunden noch einige lebende Algen vor. 
Nochmals über die Wirkung stark verd. Lösungen auf lebende Zellen.

\begin{tabular}{|c|c|c|}
\hline $\begin{array}{c}\text { Bezeichnung } \\
\text { der schädlichen } \\
\text { (verbindungsfähigen) } \\
\text { Substanz }\end{array}$ & $\begin{array}{l}\text { Verhalten bei grossen } \\
\text { Verdünnungen }\end{array}$ & $\begin{array}{c}\text { Sonstige } \\
\text { Bemerkungen }\end{array}$ \\
\hline $\begin{array}{l}\text { Übermangansaures } \\
\text { Kali (Kalium- } \\
\text { permanganat) }\end{array}$ & $\begin{array}{l}\text { Algen sterben in Lösung } 0,002 \% \\
\text { binnen } 6 \text { Stunden zum Teil ab; } \\
\text { Infusorien bleiben dabei am Leben. } \\
0,001 \% \text { ist auch für die Algen } \\
\text { unschädlich; Infusorien sterben in } \\
0,005 \% \text { ab. }\end{array}$ & $\begin{array}{l}0,001 \% \text { verzögert die } \\
\text { Fäulnis etwas. }\end{array}$ \\
\hline $\begin{array}{l}\text { Wasserstoffsuper- } \\
\text { oxyd }\end{array}$ & $\begin{array}{l}0,01 \% \text { tötet Infusorien binnen } 15 \\
\text { bis } 30 \text { Minuten ( } \mathrm{Pan} \text { eth); } 0,005 \% \\
\text { ist nicht für alle Individuen töd- } \\
\text { lich. - Vicia und Trianea ertragen } \\
0,1 \% \mathrm{H}_{2} \mathrm{O}_{2} \text { einige Zeit. }\end{array}$ & \\
\hline Chlorsaures Kali & $\begin{array}{l}0,01 \% \text { macht Buchweizenkeimlinge } \\
\text { binnen } 3 W \text { ochen unter Erbleichen } \\
\text { absterben; Spirogyren sterben } \\
\text { nach mehreren Tagen. - Aërobe } \\
\text { Pilze sollen (uach Binz) bis zu } \\
3 \% \text { vertragen. }\end{array}$ & $\begin{array}{l}\text { Es scheint, dass } \mathrm{KClO}_{3} \\
\text { vorwiegend auf die } \\
\text { Chlorophyllapparate } \\
\text { wirkt. }\end{array}$ \\
\hline Blausäure & $\begin{array}{l}\text { 1\% tötet Paramäcien augenblick- } \\
\text { lich; } 0,1 \% \text { aber selbst binnen } \\
4 \text { Tagen nicht, auch nicht bei } \\
\text { Anwendung von sehr viel Lösung. } \\
\text { 1: } 430 \text { tötet Droseratentakel } \\
\text { (Darwin). - Warmblüter werden } \\
\text { durch Spuren Blausäure getötet } \\
\text { (Lähmung des Atmungszentrums). }\end{array}$ & $\begin{array}{l}\text { Conferven werden durch } \\
0,1 \% \text { nicht getötet, } \\
\text { wohl aber durch } 1 \% \text { ige } \\
\text { Lösung, bei genügen- } \\
\text { der Menge dieser } \\
\text { Lösung (s. nachher). }\end{array}$ \\
\hline $\begin{array}{l}\text { Hydroxylamin (salz- } \\
\text { saures) }\end{array}$ & $\begin{array}{l}\text { Maiskeinlinge werden d. } 0,01 \% \text { ige } \\
\text { Lösung getötet }(0 . \text { L o e w); ebenso } \\
\text { Helianthuskeimlinge. Färulnispilze } \\
\text { wachsen nicht bei Gegenwart von } \\
0,01 \% .0,001 \% \text { tötet Diatomeen, } \\
0,005 \% \text { Infusorien. }\end{array}$ & $\begin{array}{l}\text { Frösche werden durch } \\
0,002 \text { bis } 0,005 \% \\
\text { Hydroxylamin getötet } \\
\text { (Raimu d und } \\
\text { Bertoni). }\end{array}$ \\
\hline Phenylhydrazin & $\begin{array}{l}\text { 1: } 50000 \text { tötet Diatomeen, Oscillarien, } \\
\text { Rotatorien, Infusorien (0. L o e w). } \\
0,05^{\circ} / 0 \text { hindert Pilzentwicklung } \\
\text { in guten Nährlosungen. }\end{array}$ & \\
\hline Koffein & $\begin{array}{l}1 \% \text { tötet. } \\
0,05 \text { bis } 0,01 \% \text { bewirkt Aggre- } \\
\text { gationserscheinungen, ohne die } \\
\text { Zellen zu töten. }\end{array}$ & $\begin{array}{l}\text { Für Warmblüter ein } \\
\text { relativ schwaches Gift, } \\
0,3 \text { g Einzelgabe übt } \\
\text { auf den Menschen } \\
\text { keine merkliche nach- } \\
\text { teilige Wirkung. }\end{array}$ \\
\hline Strychnin (Nitrat) & $\begin{array}{l}1 \% \text { tötet Infusorien binnen einigen } \\
\text { Minuten; } 0,1 \% \text { totet erst binnen } \\
10 \text { Minuten; } 0,01 \% \text { tötet erst } \\
\text { binnen } 12 \text { Stunden (noch nicht } \\
\text { binnen } 1 / 2 \text { Stunde). - Algen werden } \\
\text { durch } 0,1 \% \text { nicht getötet, wohl } \\
\text { aber durch } 1 \% \text {. }\end{array}$ & $\begin{array}{l}\text { Die getöteten Infusorien } \\
\text { zeigen körnige Trü- } \\
\text { bung. }\end{array}$ \\
\hline $\begin{array}{l}\text { Essigsaures Chinin } \\
\text { (Chininazetat) }\end{array}$ & $\begin{array}{l}0,1 \% \text { tötet Infusorien binnen } \\
5 \text { Minuten. } 0,01 \% \text { tötet sie } \\
\text { binnen } 24 \text { Stunden nicht. } 0,25 \% \\
\text { verhindert die Keimung von } \\
\text { Penicilliumsporen (Manass ein). }\end{array}$ & $\begin{array}{l}\text { Körnige Trübung zeigt } \\
\text { die Bildung einer un- } \\
\text { löslichen Verbindung } \\
\text { mit Plasmaeiweiss an. }\end{array}$ \\
\hline
\end{tabular}




\begin{tabular}{|c|c|c|}
\hline $\begin{array}{c}\text { Bezeichnung } \\
\text { der schädlichen } \\
\text { (verbindungsfähigen) } \\
\text { Substanz }\end{array}$ & $\begin{array}{l}\text { Verhalten bei grossen } \\
\text { Verdünnungen }\end{array}$ & $\begin{array}{l}\text { Sonstige } \\
\text { Bemerkungen }\end{array}$ \\
\hline $\begin{array}{l}\text { Essigsaur. Morphium } \\
\text { (Morphiumazetat) }\end{array}$ & $\begin{array}{l}\text { In } 0,1 \% \text { bleiben Paramäcien } 48 \text { Std. } \\
\text { am Leben. Diatomeen, Clado- } \\
\text { phoren und Vaucherien sterben } \\
\text { zum Teil ab. }\end{array}$ & $\begin{array}{l}\text { Morphiumazetat ist we- } \\
\text { niger schädlich als } \\
\text { Chinin, Strychnin. }\end{array}$ \\
\hline Salzsaures Nikotin & $\begin{array}{l}0,1 \% \text { tötet Infusorien binnen } \\
1 / 2 \text { Stunde nicht, wohl aber } \\
\text { binnen } 24 \text { Stunden. 0,01 \% tötet } \\
\text { binnen } 24 \text { Stunden nicht. }\end{array}$ & \\
\hline Formaldehyd & $\begin{array}{l}0,1 \% \text { tötet Infusorien momentan; } \\
0,01 \% \text { binnen } 5 \text { bis } 10 \text { Minuten; } \\
0,001 \% \text { lässt sie } 3 \text { Tage lang } \\
\text { unverändert. Fäulnisbakterien } \\
\text { werden durcl. Konzentration bis } \\
\text { zu } 0,002 \% \text { an der Entwicklung } \\
\text { gehindert. }\end{array}$ & $\begin{array}{l}\text { Typhusbazillen werden } \\
\text { durch } 1: 20000 \text { ge- } \\
\text { tötet, } 1: 40000 \text { an } \\
\text { der Entwicklung ge- } \\
\text { schwächt. }\end{array}$ \\
\hline Äthylaldehyd & $\begin{array}{l}0,02 \% \text { tötet Vaucherien und Con- } \\
\text { ferven binnen } 24 \text { Stunden. } 0,1 \% \\
\text { hindert die Fäulnis, } 0,02 \% \text { nicht } \\
\text { mehr. }\end{array}$ & $\begin{array}{l}\text { Bei sehr grosser Ver- } \\
\text { dünnung }(0,01 \%) \text { ist } \\
\text { er ein Nährstoff (C) } \\
\text { Quelle) für Schimmel }\end{array}$ \\
\hline Oxybenzaldehyd & $\begin{array}{l}\text { Die Orthoverbindung hindert bei } \\
0,02 \% \text { die Fäulnis, die Para- } \\
\text { verbindung nicht mehr. }\end{array}$ & und Bakterien. \\
\hline Paraldehyd & $0,002 \%$ tötet Algen binnen $24 \mathrm{Std}$. & \\
\hline Anilinfarben & $\begin{array}{l}0,1 \% \text { Diamant - F u chsin tötet } \\
\text { Mikroorganisment; } 0,01 \% \text { eben- } \\
\text { falls, wenn die Lösungsmenge } \\
\text { gross genug ist. Methyl- } \\
\text { violet verhält sich ähnlich; } \\
\text { hier wurde die Abtötung sogar } \\
\text { noch mit } 0,001 \% \text { versucht und } \\
\text { erhalten. Ähnlich Viktoria- } \\
\text { bla u usw. }\end{array}$ & $\begin{array}{l}\text { Man kann alle Stadien } \\
\text { der Färbung und die } \\
\text { allmähliche Abtötung } \\
\text { an Infusorien unter } \\
\text { dem Mikroskop ver- } \\
\text { folgen. }\end{array}$ \\
\hline Gerbstoffe & $\begin{array}{l}1 \% \text { Tannin tötet Infusorien augen- } \\
\text { blicklich; 0,1\% binnen wenigen } \\
\text { Minuten (nur die jurgen Indivi- } \\
\text { duen widerstehen länger). 0,01\% } \\
\text { schadet nicht. Katechugerbsäure } \\
\text { und Moringerbsäure verhalten } \\
\text { sich ähnlich. }\end{array}$ & $\begin{array}{l}\text { Das Absterben erfolgt } \\
\text { unt. körniger Trübung } \\
\text { (Gerbstoffeiweiss un- } \\
\text { löslich). }\end{array}$ \\
\hline
\end{tabular}

Unter allen Giften zeichnen sich, wie aus vorstehender Übersicht hervorgeht, die Metalle der Kupfergruppe, Kupfer, Silber, Quecksilber, durch die grösste Reaktionsfähigkeit aus. Kein anderes Gift bringt noch bei Verdünnung 1:100 Millionen oder gar 1:1000 Millionen eine schädliche Wirkung hervor. Ausgenommen könnten höchstens die speziellen Nervengifte sein, die oft in geringster Quantität bestimmte Nervenzentren lähmen oder töten und damit das ganze Tier zum Absterben bringen, wie z. B. die Blausäure, die 
Nochmals über die Ẉirkung stark verd. Lösungen auf Iebende Zellen. 223

Alkaloide usw. Man weiss nun freilich nicht genau, wie gross die Verdünnung ist, in welcher das betr. Gift faktisch zur Einwirkung auf die Ganglienzellen gelangt.

Fälle, in denen das Gift schon bei Verdünnung 1: 100000 auf Infusorien oder niedere Pflanzen wirkt, sind nicht selten. Formaldehyd geht nahe an diese Grenze hin, Anilinfarben erreichen dieselbe oft, Uranazetat, Chlor, Salzsäure usw. ebenfalls.

Will man das feststellen, so ist stets darauf zu achten, dass grössere Mengen von Lösung auf relativ kleine Mengen von Versuchsobjekten einwirken gelassen werden, weil sonst die Gesamtmenge des Giftes nicht ausreicht, um die scbädliche Wirkung zu Ende zu führen.

Auch ist in solchen Fällen oft eine längere Versuchsdauer einzuhalten. Manchmal tritt freilich sogar bei Verdünnung $0,001 \%$ die Giftwirkung fast augenblicklich hervor, was entweder auf einer sehr grossen Reaktionsgeschwindigkeit und Diffusionsgeschwindigkeit des betr. Stoffes oder darauf beruhen kann, dass die zur Vergiftung nötige Gesamtmenge des Stoffes eine relativ kleine ist, so dass die zur Aufsammlung nötige Zeit schon aus diesem Grunde nur kurz zu sein braucht.

Viele Gifte aber wirken überhaupt nur bei Verdünnung $0,1 \%$ oder gar $1 \%$ schädlich ein, so dass man auch bei Anwendung grosser absoluter Mengen des Giftes die schädliche oder tödliche Wirkung nicht erzielen kann, wenn man sich stärker verdünnter Lösungen des Giftes bedient.

So kann man Infusorien mit schwefelsaurem Mangan nur bei Anwendung $1 \%$ iger Lösung vergiften; $0,1 \%$ ist nicht wirksam.

$0,01 \%$ essigsaures Blei ist. völlig unwirksam, selbst bei grosser Menge der Lösung; 0,1\% tötet Infusorien binnen 10 Minuten.

In den negativen Fälleu setzt eben die Reaktion zwischen Gift und Plasma überhaupt nicht ein, weil die Verdünnung für diese chemische Reaktion zu gross ist.

Eine andere Art, die Giftigkeit einer Substanz zu bemessen, ist die, dass man die absolute $Q$ uantität des Giftes angibt, welche zur Tötung des lebenden Organismus pro Gramm oder pro Kilo nötig ist. In medizinischen Werken ist diesen Angaben grosse Aufmerksamkeit geschenkt, während ausserhalb derselben die Abschätzung der Giftigkeit meist nach dem Grade der Verdünnung geschieht, bei 
der die betreffenden Substanzen noch eine Giftwirkung auszuüben imstande sind.

Da die Feststellung der quantitativen Giftwirkung bei Pflanzen viel zuverlässiger ist als bei höheren Tieren, wenigstens bei solchen Pflanzen, die aus lauter gleichartigen Zellen aufgebaut sind, wie gewisse Fadenalgen, ferner die Hefe usw., so dürften einige Versuche in dieser Richtung von Interesse sein. Denn die höheren Tiere bestehen ja immer aus zahlreichen sehr differenten Geweben, von denen vielleicht das eine reagiert, das andere nicht. Wir kennen ja viele Gifte, die spezielle Gifte für Nerven sind und unter diesen in erster Linie wiederum eine bestimmte Art von Ganglien angreifen. Die Wirkung des Giftes hier in der Weise abzuschätzen, dass man sagt, ein Gramm des Giftes ist tödlich pro so und so viele Kilogramm Tier, hat nur in gewissem Sinne Berechtigung. Bei Spirogyren, Conferven, Vaucherien ist jede Zelle wie die andere; sie beteiligen sich alle in gleicher Weise an der Reaktion gegen Gifte. Also kann hier wirklich eine quantitative Schätzung Platz greifen.

Bezüglich der Sublimatlösung habe ich folgende Versuche gemacht: $10 \mathrm{~g}$ Algen (Spirogyren) wurden in $50 \mathrm{ccm}$ einer $0,0001 \%$ igen Sublimatlösung gebracht. Zunächst keine Veränderung; nach zwei Stunden Farbe unverändert, ebenso Turgor. Unter dem Mikroskop zeigten sich nur einzelne von den Clorophyllbänder abgelöst und in Unordnung geraten, nach 24 Stunders die Algen grün und nicht abgestorben, mit Turgor. 0,5 $\mathrm{mg}$ Sublimat (in obiger Verdünnung) töten also $10 \mathrm{~g}$ Algen nicht binnen zwei Stunden, auch nicht binnen 24 Stunden. b) $10 \mathrm{~g}$ Algen wurden in $50 \mathrm{ccm}$ einer $0,001 \%$ igen Sublimatlösung gebracht. Zunächst erfolgte keine Veränderung. Nach 24 Stunden war aber die ganze A]genmasse verfärbt und ohne Turgor; unter dem Mikroskop zeigten die meisten Zellen solche Veränderungen (Ablösung der Chloroplyyllbänder, Kontraktion des Plasmaschlauches, Granulation in diesem etc), dass sie als tot betrachtet werden mussten.

Wir können also sagen, dass $50 \mathrm{ccm}$ einer $0,001 \%$ igen Sublimatlösung, d. i. $0,0005 \mathrm{~g}$ oder $0,5 \mathrm{mg}$ Sublimat, noch ausreichen, um $10 \mathrm{~g}$ Algen abzutöten; nicht mehr ausreichend sind $50 \mathrm{ccm}$ einer 0,0001\%igen Sublimatlösung oder $0,00005 \mathrm{~g}$ d. i. $0,05 \mathrm{mg}$ Sublimat.

B laus ä ure wurde in der Stärke $0,1 \%$ hergestellt. Von dieser Lösung wurden a) $20 \mathrm{ccm} \mathrm{zu} 10 \mathrm{~g}$ Conferven (feucht gewogen), 
Nochmals über die Wirkung stark verd. Lösungen anf lebende Zellen. 225

b) $40 \mathrm{ccm} \mathrm{zu} 10 \mathrm{~g}$ Conferven, c) $100 \mathrm{ccm}$ zu $10 \mathrm{~g}$ Algen gesetzt; die absolute Menge Gift betrug also bei a) 0,02 g, b) 0,04 g, c) $0,1 \mathrm{~g}$ Blausäure auf $10 \mathrm{~g}$ Conferven, feucht gewogen.

Nach 24 Stunden waren die Algen in sämtlichen drei Versuchen noch durchaus lebend.

Nach weiteren 24 Stunden zeigte sich bei sämtlichen Versuchen noch keine Veränderung, nach vier Tagen (im ganzen) ebenfalls nicht.

Also ist $0,1 \%$ Blausäure überhaupt nicht imstande, Conferven zu töten; an der absoluten Menge kann es nicht liegen, da $0,1 \mathrm{~g}$ Blausäure (HCN) doch sicher ausreicht, um $10 \mathrm{~g}$ Algen (feucht gewogen) wenigstens zu schädigen. Die Reaktion setzt eben gar nicht ein, 0,1\% ige Blausäure vermag gar nicht auf das Algenplasma zu reagieren.

Nun wurde bei allen drei Versuchen die $0,1 \%$ ige Blausäure durch $1 \%$ ige ersetzt. Nach 24 Stunden waren die Algen in b und c abgestorben und total verfärbt, die in a zum grossen Teil noch grün und lebend. Unter dem Mikroskop zeigte sich, dass bei $b$ und $c$ sämtliche Protoplasten stark kontrahiert, d. h. von der Zellwand abgelöst waren, während bei a dies nur an einem Teil der Zelle zu bemerken war.

Also ist $0,2 \mathrm{~g}$ reine (wasserfreie) Blausäure nicht imstande, $10 \mathrm{~g}$ Confervenvollständig zu töten; dagegen reicht $0,4 \mathrm{~g}$ und noch besser $1 \mathrm{~g} d \mathrm{azu}$ aus.

Demgegenüber ist es staunenswert, dass bei Meerschweinchen 1/1000 mg wasserfreie Blausäure genügt, um den Tod herbeizuführen. Offenbar liegt hier eine Wirkung auf bestimmte Teile des Nervensystems vor. Nach den Angaben der Lehrbücher für Arzneimittellehre erfolgt der rapide Tod bei Warmblütern durch rasche Lähmung des Atmungszentrums.

Über Strychninsalze wurden ähnliche Proben gemacht, nur war die zu den Versuchen verwendete Alge diesmal Zygnema, nicht mehr Conferva, was übrigens nach meinen sonstigen Erfahrungen nicht viel ausmachen dürfte.

a) $10 \mathrm{~g}$. Algen wurden in $50 \mathrm{ccm}$ einer $0,05 \%$ igen Strychninnitratlösung gebracht, b) $10 \mathrm{~g}$ Algen in $200 \mathrm{ccm}$ einer $0,05 \%$ igen Strychninnitratlösung.

Nach 24 Stunden erwiesen sich bei b sämtliche Algen unter dem Mikroskop als abgestorben unter starker Verschiebung der Zellorgane, bei a war der weitaus grösste Teil noch am Lebeu und ungestört. 
226 Th. Bokorny: Nochmals über die Wirkung stark verd. Lösungen etc.

Also reicht 0,1 g Strychninnitrat aus, um $10 \mathrm{~g}$ Algen zu töten, $0,025 \mathrm{~g}$ aber nicht:

Während also bei Sublimat die für $10 \mathrm{~g}$ Algen tödliche Menge zwischen $0,0005 \mathrm{~g}$ und $0,00005 \mathrm{~g}$ liegt, braucht man bei Blausäure zwischen 0,4 und $0,2 \mathrm{~g}$; bei Strychninnitrat zwischen $0,1 \mathrm{~g}$ und $0,025 \mathrm{~g}$.

Bei Sublimat ist also die für Algen tödliche Dose sehr viel kleiner als bei Blausäure und Strychnin; zwischen Blausäure und Strychniu scheint eine weit geringere Differenz zu bestehen.

Weitere Untersuchungen in dieser Richtung sind geplant. 